\title{
Imaging and recording subventricular zone progenitor cells in live tissue of postnatal mice
}

\author{
Benjamin Lacar ${ }^{1,2 \ddagger}$, Stephanie Z. Young ${ }^{1,2 \ddagger}$, Jean-Claude Platel ${ }^{1,2 \dagger}$ and Angélique Bordey ${ }^{1,2 *}$ \\ 1 Department of Neurosurgery, Yale University School of Medicine, New Haven, CT, USA \\ Department of Cellular and Molecular Physiology, Yale University School of Medicine, New Haven, CT, USA
}

Edited by:

Flora M. Vaccarino, Yale University

School of Medicine, USA

Reviewed by:

Francis G. Szele, Oxford University, UK

Alejandro F. Schinder, Leloir Institute,

Argentina

*Correspondence:

Angélique Bordey, Yale University School of Medicine, 333 Cedar St, FMB 422, New Haven, CT 06520 8082, USA.

e-mail: angelique.bordey@yale.edu

'tPresent Address: Jean-Claude Platel, Department of Physiology, School of Medicine, University of Saarland, Homburg/Saar, Germany

${ }^{\ddagger}$ Benjamin Lacar and Stephanie Z. Young have contributed equally to the work.
The subventricular zone (SVZ) is one of two regions where neurogenesis persists in the postnatal brain. The SVZ, located along the lateral ventricle, is the largest neurogenic zone in the brain that contains multiple cell populations including astrocyte-like cells and neuroblasts. Neuroblasts migrate in chains to the olfactory bulb where they differentiate into interneurons. Here, we discuss the experimental approaches to record the electrophysiology of these cells and image their migration and calcium activity in acute slices. Although these techniques were in place for studying glial cells and neurons in mature networks, the SVZ raises new challenges due to the unique properties of SVZ cells, the cellular diversity, and the architecture of the region. We emphasize different methods, such as the use of transgenic mice and in vivo electroporation that permit identification of the different SVZ cell populations for patch clamp recording or imaging. Electroporation also permits genetic labeling of cells using fluorescent reporter mice and modification of the system using either RNA interference technology or floxed mice. In this review, we aim to provide conceptual and technical details of the approaches to perform electrophysiological and imaging studies of SVZ cells.

Keywords: neurogenesis, migration, proliferation, electroporation, transgenic mice, stem cells, neuroblasts, calcium imaging

\section{INTRODUCTION}

Neurogenesis persists in two centers in the adult brain, the neurogenic subventricular zone (SVZ) and the hippocampal dentate gyrus (Lledo et al., 2006; Zhao et al., 2008). In the SVZ, neural progenitor cells (also called neural stem cells), a subpopulation of astrocyte-like cells, produce transit-amplifying cells (TACs), which in turn generate neuroblasts (Doetsch et al., 1999). Neuroblasts migrate in chains ensheathed by astrocyte-like cells throughout the SVZ and along the rostral migratory stream (RMS) to the olfactory bulb (OB) (Lois et al., 1996; Peretto et al., 1997). Once in the RMS of the OB, they turn to enter the existing $\mathrm{OB}$ circuitry and differentiate into interneurons (granule cells, periglomerular cells, and to some extent glutamatergic neurons) (Luskin, 1993; Lois and Alvarez-Buylla, 1994; Brill et al., 2009).

From cell birth to the time new neurons reach their target destination, neurogenesis takes $\sim 2$ weeks minimum. Accordingly, traditional methods that visualize proliferation, migration, survival and differentiation that take from hours to weeks and generally use fixed tissue. For example, administrations of $\mathrm{BrdU}$ and subsequent fixation can reveal proliferation occuring after $2 \mathrm{~h}$, migration over a course of several days, and survival over weeks. Thus, why is studying neurogenesis in acute tissue, over a shorter time range, with electrophysiology and live imaging necessary? Live tissue approaches provide a greater understanding of the intercellular signaling relationship in the neurogenic zones. Whereas staining of receptors in fixed tissue can reveal regional and cellular location, electrophysiology and calcium imaging not only determine whether the receptor is functional, but to what extent. By manipulating these signaling processes, we can then examine their effect on neurogenesis.
Live imaging can also help study one neurogenic process, migration, directly. In the SVZ-RMS axis, neuroblasts can move several micrometers per minute. One can then genetically or pharmacologically manipulate these cells and determine the precise speed by which they move. In short, live imaging approaches therefore help address novel ideas about neurogenesis.

Electrophysiological and imaging analyses of the behavior of SVZ cells have only been recently reported. Although the techniques were in place for studying glial cells and neurons in mature networks, electrophysiology and live imaging in the SVZ met additional challenges due to the unique properties of the SVZ architecture and its cells. Indeed, the cells in the SVZ are densely packed with almost no extracellular space, thus limiting access to individual cells. SVZ cells, in particular neuroblasts, are small $(\sim 6 \mu \mathrm{m})$ and have a thin membrane and small cytoplasm and are therefore fragile compared to neurons. Due to the presence of diverse cell types touching each other in the SVZ, identifying cells has also been a major challenge for electrophysiology or live imaging. We first detail how the different cell types can be labeled, with an emphasis on our own approaches using transgenic mice and, more recently, in vivo electroporation. The electrophysiological recordings and their problems have been addressed in recent studies and will only be summarized here. The imaging techniques for studying neuroblast migration and calcium activity in diverse populations of SVZ cells are detailed with explanations provided for the choice of dyes and methods of dye labeling in transgenic mice or following genetic labeling (electroporation). Finally, we will emphasize in the conclusion that in vivo electroporation is a powerful method to genetically modify this system. 


\section{LABELING OF SVZ CELL TYPES FOR DIVERSE APPLICATIONS}

The SVZ contains at least six different cell types defined by their morphology, ultrastructure, and molecular markers (Smart, 1961; Altman, 1963, 1969; Blakemore, 1969; Privat and Leblond, 1972; Kishi, 1987; Sucher and Deitcher, 1995; Jankovski and Sotelo, 1996; Lois et al., 1996; Doetsch et al., 1997; Peretto et al., 1997; Mercier et al., 2002). The migrating neuroblasts (referred to as type A cells, Lois et al., 1996; class 1 cells, Jankovski and Sotelo, 1996; or neuronal precursors) migrate in chains to the $\mathrm{OB}$ along the RMS. A particular type of protoplasmic astrocyte (also called type B cells, Lois et al., 1996; or class 2 cells, Jankovski and Sotelo, 1996) ensheath the chains of migrating neuroblasts. More spherical and highly proliferative progenitors called TACs (or type $\mathrm{C}$ cells) form clusters next to the chains of migrating neuroblasts. The SVZ is largely separated from the ventricular cavity by a layer of ependymal cells (also called type E cells, Doetsch et al., 1997). The neuroblasts and astrocytes are the two main progenitor types located between the ependymal cell layer and the striatal parenchyma in the adult SVZ (Doetsch et al., 1997). Two additional cell types include microglial cells and NG2 cells (Aguirre et al., 2004; Goings et al., 2006; Platel et al., 2009). Regarding cell lineage, a subpopulation of astrocytes behaves as neural progenitor cells (also called stem cells) (Doetsch et al., 1999). They self-renew and generate TACs that in turn self-renew and generate neuroblasts (as well as glioblasts following injuries).
These neuroblasts migrate to the $\mathrm{OB}$ where they differentiate into granule cells, periglomerular cells and to a smaller extent glutamatergic neurons (Lledo et al., 2006; Brill et al., 2009). The lineage and architecture of the SVZ are illustrated in Figures $\mathbf{1}$ and $\mathbf{2 .}$

Several approaches can be used to label and identify cells in acute slices: transgenic mice, in vivo electroporation, and viral labeling. We will discuss all three with an emphasis on the first two options.

\section{TRANSGENIC MICE TO LABEL SPECIFIC CELL TYPES AND ADDITIONAL APPLICATIONS}

One method of labeling a specific cell population in live SVZ sections is through the use of transgenic mice in which fluorescent proteins are expressed under the control of cell-type specific promoters.

\section{Immature cells}

Several groups have generated transgenic mice using the nestin promoter. Nestin was discovered as an intermediate filament expressed in immature cells, in particular radial glia during brain development (Hockfield and McKay, 1985), and has been reported in adult SVZ cells (Wang et al., 2003a). These mice include nestin-GFP (2 lines), nestin-Cre, and inducible nestin-tTA and nestin-Cre ${ }^{\text {ERT2 }}$ mice (see Table 1 for references). GFP expression in the two lines of nestin-GFP mice display different patterns and is expressed in
A

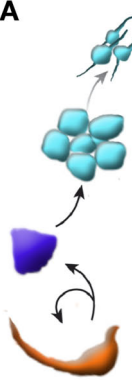

OB neurons

Neuroblasts

DCX, TuJ1

TAC

EGFR, (BLBP)

Stem cells*:

GFAP, GLAST

BLBP

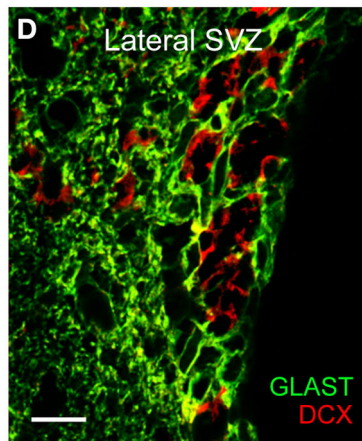

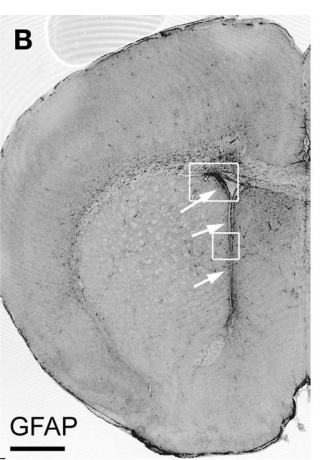
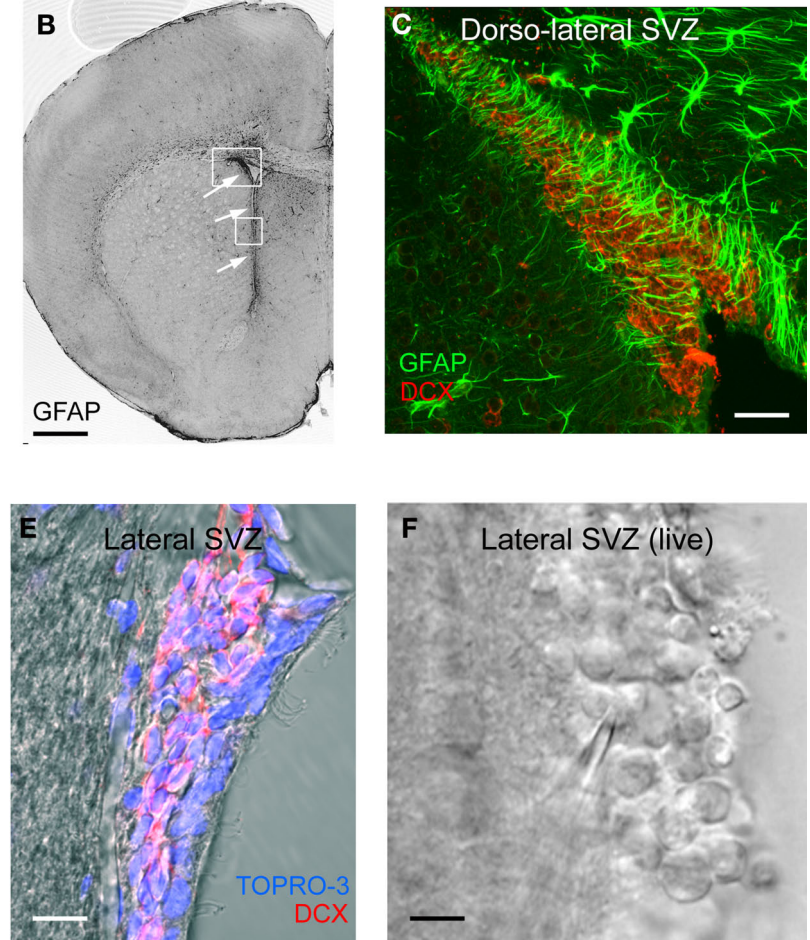

FIGURE 1 | SVZ cell lineage and antigenic properties. (A) Diagram illustrating the lineage and antigenic properties of the different SVZ progenitor cells. GFAP, glial fibrillary acidic protein; GLAST, glutamate-aspartate transporter; BLBP, brain lipid-binding protein; DCX, doublecortin; TuJ1, $\beta$ III-tubulin; TAC, transit-amplifying cells. Some, but not all, of the TACs express BLBP. (B) Photograph of GFAP immunostaining in a coronal section containing the SVZ. The arrows point to the SVZ. (C) Confocal image of GFAP (green) and DCX (red) co-immunostaining in the dorso-lateral SVZ. (D) Confocal image of GLAST (green) and DCX (red) coimmunostaining in the lateral SVZ located along the lateral ventricle (E) Confocal image of DCX (red) immunostaining and TOPRO-3 (nuclear labeling) in the lateral SVZ. (F) Image of a live coronal slice containing the lateral SVZ. The lateral ventricle is on the right and the striatum on the left. Scale bars: $500 \mu \mathrm{m}$ (B), $100 \mu \mathrm{m}$ (C), $60 \mu \mathrm{m}$ (D) and (E), $40 \mu \mathrm{m}$ (F). ${ }^{*}$ Note that presumably all stem cells express these markers, but individual markers alone are not sufficient to identify stem cells. 


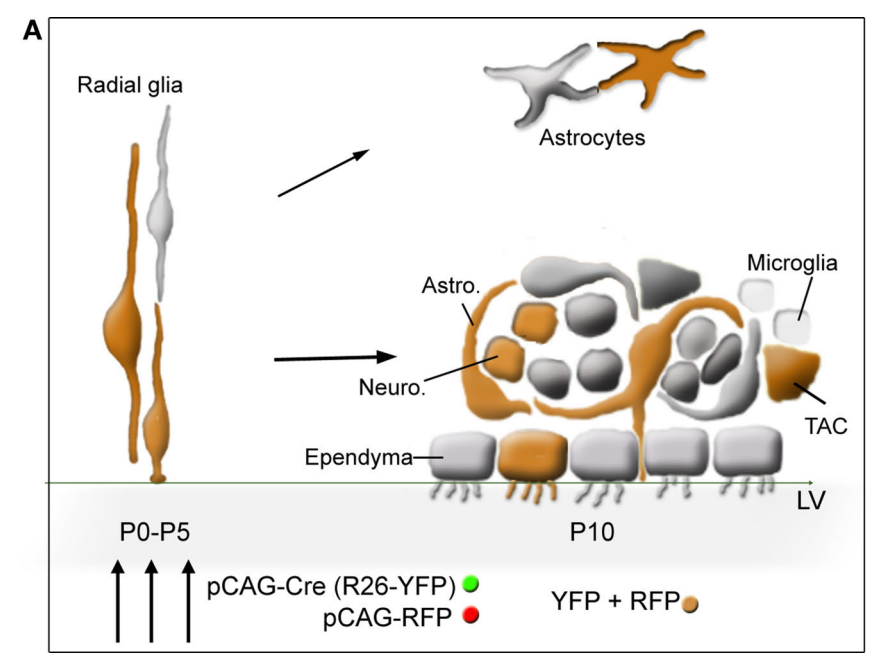

B

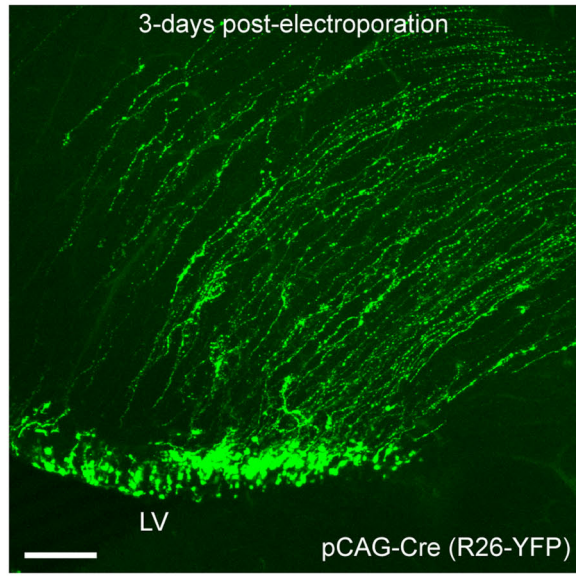

FIGURE 2 | SVZ electroporation and labeled cells. (A) Diagram illustrating: (1) the transformation of radial glia into SVZ astrocytes and ependymal cells, and parenchymal astrocytes during the first 2 weeks, (2) the cellular organization of the SVZ. Astrocyte-like cells (astro.) ensheath neuroblasts (neuro.). TACs and microglia (represented as small light cells) are scattered throughout the SVZ. Ependymal cells line the lateral ventricle (LV). (3) Co-electroporation of pCAG-driven fluorescent proteins results in protein expression into radial glia, and thus in SVZ astrocyte-like cells and ependymal cells, and the progeny of astrocyte-like cells, i.e., TAC and neuroblasts that appear orange due to both RFP and YFP co-localization. The diagram assumes a $100 \%$ co-localization, which is experimentally $80-90 \%$. (B) Confocal image illustrating the expression of yellow fluorescent protein (YFP) in radial glia following electroporation of a pCAG-Cre in Rosa26-YFP mice. Scale bar: $100 \mu \mathrm{m}$. several cell types (Nam et al., 2007; Kim et al., 2009). Nestin-Cre mice crossed with fluorescent reporter mice (e.g., Rosa26-Stop-YFP mice) results in YFP expression in a subset of SVZ cells including astrocytes and neuroblasts (Machold et al., 2003). As a result, nestin-GFP and nestin-Cre mice are not helpful for identifying subpopulations of cells in the SVZ. These mice have been used for migration studies, but data analysis is difficult because of the need to determine cell identity post-recording (Kim et al., 2009). Inducible nestin-tTA and nestin-Cre ${ }^{\text {ERT2 }}$ will label a subset of cells independent of their identity in the SVZ (Table 1; Figure 1).

\section{SVZ/RMS astrocytes}

The most common markers of mature and SVZ astrocytes include glial fibrillary acidic protein (GFAP, Figures 1B,C), glutamateaspartate transporter GLAST (also known as excitatory amino acid transporter 2, EAAT2, Figure 1D), the other glial glutamate transporter GLT-1 (EAAT1), brain lipid-binding protein BLBP (Liu et al., 2006; Wang and Bordey, 2008; Platel et al., 2009). GLT-1 has only been used by our group, but GLAST has been used by us in several articles (Bolteus and Bordey, 2004; Liu et al., 2006; Platel et al., 2009,2010) as well as at by several other groups (Braun et al., 2003; Sundholm-Peters et al., 2004; Pastrana et al., 2009). BLBP, which is a radial glia marker (Feng et al., 1994), persists in $\mathrm{GFAP}^{+}$cells as well as in a subpopulation of TACs in the postnatal SVZ (SundholmPeters et al., 2004; Balordi and Fishell, 2007; Liu et al., 2008). There is a subpopulation of S100B-expressing astrocytes in the SVZ, some of which express GFAP (Raponi et al., 2007; Platel et al., 2009), that are not discussed in this article. Transgenic mice expressing GFP under the human GFAP promoter ( $h G F A P$ ) were the first of the $h G F A P$-driven lines generated to study mature astrocytes in live tissue (Zhuo et al., 1997). Recently generated transgenic mice include: hGFAP-DsRed (Discosoma sp. red-fluorescent protein) (Noraberg et al., 2007), mouse (m) GFAP-GFP (Kuzmanovic et al., 2003), GLAST-DsRed and GLT-1-GFP (Regan et al., 2007), BLBP-GFP (Schmid et al., 2006), and hGFAP-MrgAl:GFP mice (Fiacco et al., 2007). These latter mice express a Gq-protein coupled receptor (called Mas-related gene A1, MrgA1) fused to GFP selectively in GFAP-expressing cells using the inducible tet-off system. Mice expressing the tetracycline transactivator (tTA) under the $h G F A P$ promoter ( $h G F A P$-tTA mice) were crossed to mice in which the $\mathrm{MrgAl}$ receptor was transcribed off the tet (tetO) minimal promoter (tetO-MrgA1). In the absence of doxycycline, astrocytes express MrgA1:GFP (Table 1; Figure 1).

Our lab examined three $h G F A P$-driven mouse lines that each have their own advantages and disadvantages with respect to the study of progenitor cells (Liu et al., 2006; Platel et al., 2009; Young et al., 2010). In both the $h G F A P$-GFP and -DsRed (generated by Dr. Messing's, Zhuo et al., 1997, and Jensen's group, Noraberg et al., 2007, respectively), the fluorescence is localized to the cytoplasm allowing overlay with cytoplasmic and nuclear markers such as the mitotic marker bromodeoxyuridine (BrdU, Figure 4F). All SVZ astrocytes express GFP in $h$ GFAP-GFP mice, in contrast to the $h G F A P$-DsRed mice, in which only a subset of SVZ astrocytes express DsRed for unknown reasons. In addition, the DsRed protein having a half-life of 4 days persists in TACs and neuroblasts that were recently generated from DsRed-positive astrocytes (Young et al., 2010). Although the fluorescence in neuroblasts is less intense than in astrocytes, this is a serious limitation for unambiguous identification of red-fluorescent cells as astrocytes. These two mouse lines are not optimal for calcium imaging due to the cytoplasmic presence of GFP in the former (same wavelength as the green calcium indicator dye) and to the persistence of DsRed in neuroblasts in the latter. However, in $h G F A P-M r g A 1: G F P$ mice, GFP is expressed in the membrane allowing visualization of an outline 
Table 1 | Transgenic mice to study the different cell types in the SVZ.

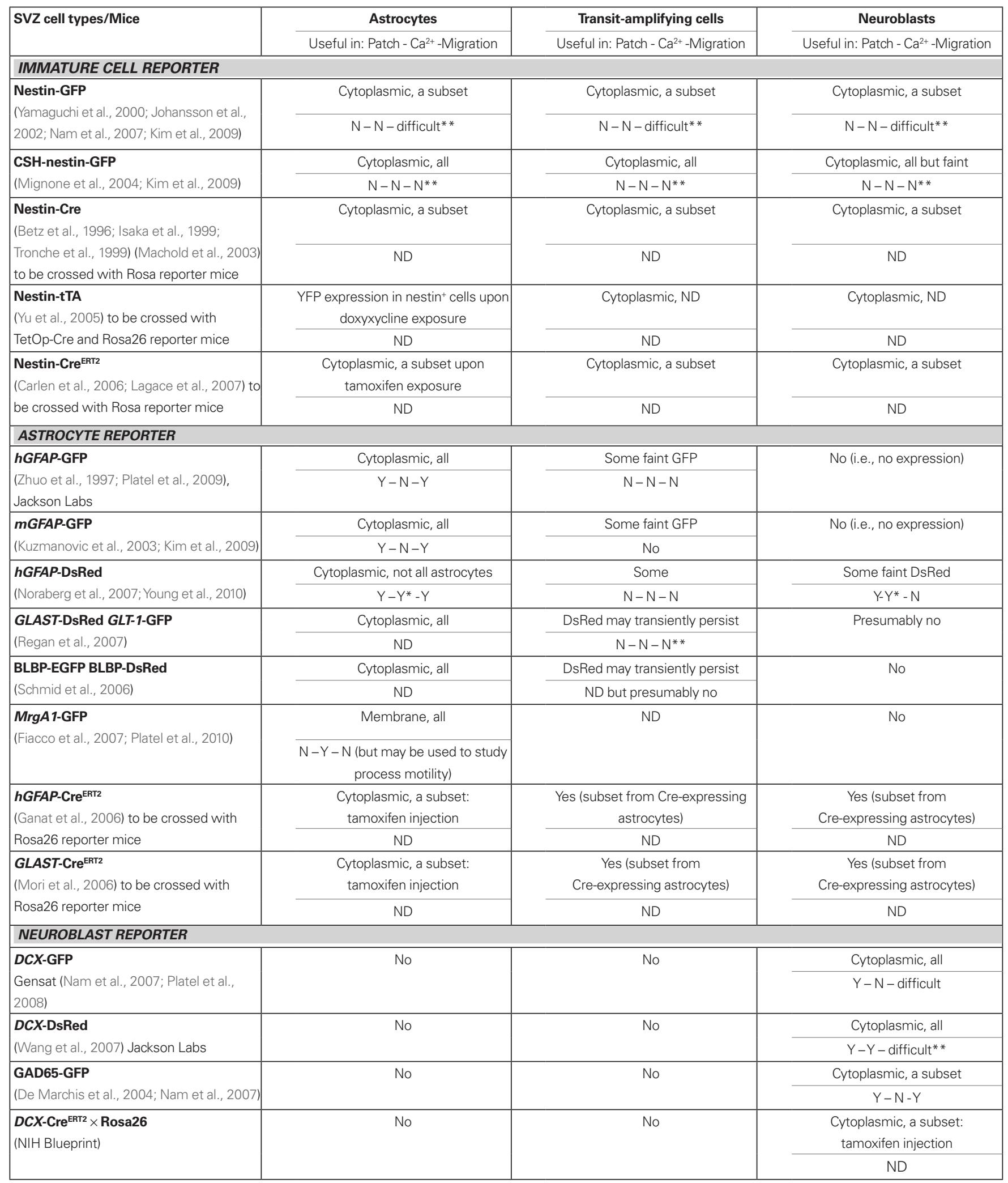

$N D$, not determined.

${ }^{*}$ Caveat since DsRed, although at low fluorescence intensity, persists in neuroblasts.

**The answer $N=n o, Y=$ yes, is based on published data and our recommendations. 
of SVZ astrocytes (see Figure 6D). This is advantageous for both immunostaining membrane proteins like GLAST and for calcium imaging. Indeed, this allows calcium imaging where dyes are in a similar emission spectrum as GFP (e.g., Fluo-4 AM), which would otherwise be obstructed with cytoplasmic localization of GFP. In addition, confirmation of the identity of GFP-fluorescent cells as astrocytes can be strengthened by carefully noting where membrane-bound GFP resides and, after loading the calcium-sensitive dye, applying the MrgA1-specific peptide phe-leu-arg-phe amide (FLRFa) to note which cells are responding specifically to the peptide. FLRFa is a selective agonist of MrgA1 that does not bind to endogenous receptors (Figures $6 \mathrm{~F}-\mathrm{H}$ ).

Other BAC transgenic mouse lines have been generated through Gensat $^{1}$ that display preferential astrocytic expression of GFP such as Aldh1l1-GFP. However, these different mice have not been evaluated for GFP expression in the SVZ. Other lines include inducible transgenic Cre ${ }^{\mathrm{ERT} 2}$ mice. When crossed with fluorescent reporter mice (e.g., Rosa26-Stop-YFP or Rosa26-Stop-tdTomato mice), injection of tamoxifen induces translocation of Cre recombinase from the cytoplasm to the nucleus. This results in excision of the stop sequence and induces YFP or tdTomato expression selectively in cells expressing Cre ${ }^{\mathrm{ERT} 2}$. $h G F A P-\mathrm{Cre}^{\mathrm{ERT} 2}$ and GLAST-Cre ${ }^{\mathrm{ERT} 2}$ have been recently generated allowing lineage studies in the SVZ (Ganat et al., 2006; Mori et al., 2006). These mice are not optimal for selectively studying astrocytes since TACs and neuroblasts would also express YFP or tdTomato.

\section{Neuroblasts}

Several transgenic mouse lines have been generated, allowing selective identification of neuroblasts based on the following markers: doublecortin (DCX, Figures 1C-E), $\beta$ III-tubulin (TuJ1), and the glutamic acid decarboxylase $65 \mathrm{kDa}$ (GAD-65). DCX-GFP and DCX-DsRed mice are now commercially available at Gensat and at Jackson Labs (Wang et al., 2007), respectively. DCX-GFP mice are ideal for immunostaining studies and have been used for migration studies (Nam et al., 2007; Platel et al., 2008). However, the presence of GFP in every neuroblast makes such migration studies difficult because it is difficult to distinguish individual neuroblasts. The DCX-DsRed mice are suited for performing calcium imaging in neuroblasts, though this has not yet been done in these mice. TuJ1-GFP mice have been generated but have not been examined in the postnatal SVZ (Attardo et al., 2008). GAD-65-GFP target subpopulations of neuroblasts allowing migration studies of at least a specific subpopulation of neuroblasts (De Marchis et al., 2004; Nam et al., 2007). About 30\% of the migrating cells express GAD65-GFP (De Marchis et al., 2004; Nam et al., 2007). It, however, remains unclear whether cells expressing one of the GADs will become GABAergic interneurons or lose GAD expression and become dopaminergic interneurons (Table 1; Figure 1).

Other $\mathrm{Cre}^{\text {ERT2 }}$ mouse lines have been generated through the NIH Neuroscience Blueprint Cre driver network ${ }^{2}$ and will become available through Jackson Labs. One of these lines is the DCX-Cre ERT2 $^{\text {ERT }}$ that can be used to label neuroblasts upon tamoxifen injection once crossed with a Rosa 26 reporter mice. In the DCX-Cre ${ }^{\text {ERT2 }} \times$ Rosa26-

${ }^{1}$ gensat.com

${ }^{2}$ credrivermice.org
Stop-tdTomato, the number of neuroblasts turning red can likely be titrated depending on the quantity of injected tamoxifen. These mice will thus be helpful for calcium imaging, electrophysiology, and migration studies. It is important to briefly note that the inducible mouse lines can be crossed with mice in which a gene of interest is flanked by LoxP sites; upon tamoxifen injection, Cre induction would result in excision of both the Stop sequence and the gene of interest. This approach leads to the selective genomic removal of a gene and thus the protein of interest in neuroblasts. The obvious limitation of this approach for genetic manipulations is the need of a transgenic mouse line for each gene of interest.

\section{Transit-amplifying cells}

At present, a transgenic mouse line that labels all and only TACs in adult tissue has not been generated. TACs express Mash 1 (Parras et al., 2004) and Mash1-GFP mice have been generated (Gensat). However, both TACs and neuroblasts express GFP (Kim et al., 2009), making the study of TACs difficult due to the need for post-recording immunostaining. One reliable marker is perhaps EGF receptor (EGFR), as recently shown in both the neonatal and adult SVZ (Cesetti et al., 2009; Pastrana et al., 2009). These cells are relatively rare and constitute $5-10 \%$ of all SVZ cells depending on the rostral-caudal position along the SVZ (Doetsch et al., 1997). In addition, there may be multiple markers as these cells progress down the lineage, but they have yet to be determined. Olig2-expressing progenitors have been shown to act as gliogenic progenitors in neonatal mice (Aguirre and Gallo, 2004; Marshall et al., 2005) and may be generated from EGFR-expressing cells or directly from GFAP-expressing progenitor cells (Platel et al., 2009) (Table 1; Figure 1).

\section{Ependymal cells}

While no groups have reported transgenic mice for ependymal cells, they are easy to identify with differential interference contrast (DIC) optics (see Figure 4F). Cilia are especially noticeable as hair-like protrusions from cuboidal cells lining the lateral ventricle, which beat rapidly in healthy acute slices (Genzen et al., 2009a,b). Ependymal cells also have noticeable lipid droplets (Table 1).

\section{Microglia}

Microglia selectively express $\mathrm{Cx} 3 \mathrm{cr} 1$ receptors. Transgenic mice expressing Cx3Cr1-GFP in the locus of Cxcr1 receptors are viable and a useful tool for studying microglia in live tissue (Jung et al., 2000) (Jackson labs).

\section{NG2 cells}

NG2 cells are better known as oligodendrocyte progenitor cells (Polito and Reynolds, 2005) and were so-named because of their expression of the NG2 proteoglycan [also known as chrondroitin sulfate proteoglycan 4 (CSPG4)]. The Nishiyama lab created transgenic mice in which DsRed is expressed under the NG2 promoter using BAC modification techniques (Zhu et al., 2008). In the neonatal SVZ, NG2 cells have been shown to act as TACs generating both neurons and oligodendrocytes (Aguirre et al., 2004), but only a glial fate has been reported in adult animals (Komitova et al., 2009). In the adult SVZ, a few SVZ cells with a classical OPC morphology (flat and bushy) are found by immunostaining for 
NG2 (Platel et al., 2009). One limitation in using NG2 for OPC labeling is that pericytes, which are the smooth muscle cells of capillaries, also express NG2. This could lead to confusion while studying NG2-postive OPCs, despite the fact that their morphology is strikingly different.

\section{VIRAL LABELING}

Many viral vectors are now available that can be used for gene transfer into cells including SVZ cells (for review and references on viruses, Naldini, 1998; Washbourne and McAllister, 2002; Kane et al., 2010). Infection of SVZ cells with replication deficient retroviral labeling has been used to label cycling progenitor cells in the neonatal SVZ in the early 1990s (Levison and Goldman, 1993). This approach is still routinely used by many investigators to label a cohort of proliferating neuroblasts at any given time. Other viruses used to study neurogenesis include lentivirus and adenovirus. Adenoviruses tend to infect glial cells, in particular radial glia and astrocytes, but will also infect neurons (Akli et al., 1993; Davidson et al., 1993; Le Gal et al., 1993). Adenovirus have been deposited on the surface of the neonatal brain where it enters the endfeet of radial glial cells and is then retrogradely transported to the cell body (Merkle et al., 2007; Ventura and Goldman, 2007). One study also used a VSV-G (vesicular stomatitis virus $\mathrm{G}$ ) pseudotyped lentivirus that is not retrogradely transported and was used to control for viral diffusion from the site of infection. Unlike retroviruses, which only label cells in the cell cycle, lentiviruses infect both cycling and non-cycling cells. This makes it advantageous for labeling the quiescent stem cell population. The use of lentivirus in the study of the SVZ is gaining in popularity (Rubinson et al., 2003) (for review see Naldini, 1998). To label the different cell types, investigators have the option to use selective promoter-driven expression of GFP or RFP. For example, a $\alpha 1$-tubulin and nestin promoters driving GFP expression were previously used to visualize and then isolate neuroblasts and less committed neural progenitors in vitro (Roy et al., 2000). It will be important to carefully validate the expression pattern of the transgenic line, as expected.

\section{POSTNATAL IN VIVOELECTROPORATION}

Electroporation in vivo provides a valuable technique for visualizing, tracking, and genetically manipulating cells in the SVZ (Figures 2 and 3). The lateral ventricle is readily accessible through minimally invasive techniques during the neonatal period. This technique has been previously reported by several groups (Wang et al., 2005; Platel et al., 2007a,b, 2008, 2009, 2010; Barnabe-Heider et al., 2008; Boutin et al., 2008; Chesler et al., 2008).

In vivo electroporation of DNA plasmid is performed in postnatal day (P) 0-5 mouse pups, which requires no surgical procedures (see additional details in Supplementary Material). The DNA plasmid $(1-2 \mu \mathrm{g} / \mu \mathrm{l})$ is injected with a beveled and pulled patch pipette in the lateral ventricle about $1 \mathrm{~min}$ prior to applying three $50 \mathrm{~ms}$-pulses at $130 \mathrm{~V}$ and at $1 \mathrm{~Hz}$ using a pulse generator (ECM830 BTX). A large selection of plasmids at an affordable price is commercially available at addgene.com. For example, we used the following plasmids: pCAG-GFP (\#11150), pCAG-DsRed (\#1151), pCAG-Cre:GFP (\#13776). Technically, electroporated cells are radial glial cells that populate the neonatal SVZ and send processes along the lateral ventricle (Figure 2). Radial glia transform into both ependymal cells and SVZ astrocytes during the neonatal period (Paterson et al., 1973; Merkle et al., 2004). These specialized astrocytes generate TACs and neuroblasts, which migrate to the $\mathrm{OB}$ in 7-14 days. As a result, at 2 weeks postelectroporation with a plasmid containing GFP under a cytomegalovirus (CMV) early enhancer/chicken $\beta$-actin (CAG) promoter, GFP-expressing cells include: ependymal cells, SVZ astrocytes, and neuroblasts in the SVZ, RMS, and OB (diagrams in Figures 2A and $3 \mathrm{C}$ ). There are also mature astrocytes nearby in the striatum that express GFP because radial glia also transform into striatal astrocytes during the neonatal period (diagram in Figure 2A).

We examined GFP-expressing cells up to 2 months postelectroporation in the SVZ and OB. First, GFP-expressing neurons persisted in the granule cell and periglomerular cell layer in the $\mathrm{OB}$ at 2 month post-electroporation. Granule cells displayed large dendritic arbors with spines in the external plexiform layer (Figure 3F). In the SVZ GFP-expressing cells were ependymal cells (based on morphology) and GLAST, BLPB or GFAP-expressing cells, i.e., astrocytes (data not shown). These data suggest that the CAG promoter remains active in cells up to 2 months postelectroporation. Using only a CMV promoter resulted in the loss of GFP-expressing cells in 1-2 weeks (data not shown). However, there is an important limitation of neonatal electroporation in wildtype mice. At 3-4 weeks post-electroporation no GFP-expressing neuroblasts are visible in the SVZ and RMS en route to the OB (Figure 3). Considering the stability of the pCAG-GFP expression, one explanation is plasmid dilution over the course of successive cell divisions in TACs and neuroblasts. Indeed, the SVZ astrocytes are expected to rarely divide and thus maintain high copy number of the plasmid while their daughter cells, the TACs, are highly proliferative leading to plasmid dilution following every division. Because TACs generate neuroblasts, the plasmid will also be diluted in neuroblasts over time. Collectively, in vivo electroporation in neonatal wild-type mice allows the study of SVZ astrocytes up to 2 months and perhaps longer after birth, the study of neuroblasts (patch, migration or calcium) only during the neonatal period, and the study of neuronal integration in a young network.

A first alternative to counteract the problem of plasmid dilution is to use Rosa26 reporter mice and electroporating a Cre recombinase (Cre)-containing plasmid (Figure 3). In such mice, Cre will induce genomic expression of YFP or tdTomato following excision of a Stop sequence. There is thus no plasmid dilution in TACs. As a result at 2 months post-electroporation, neuroblasts are still observed throughout the SVZ and the RMS. This approach allows permanent labeling of SVZ astrocytes, TACs and a subset of neuroblasts that can subsequently be recorded and monitored in live tissue. Crossing hGFAP-MrgA1-GFP mice with Rosa26-StoptdTomato would allow selective visualization of astrocytes and neuroblasts for example. As mentioned later in this review, this approach also allows knocking out genes when using floxed mice (e.g., mice where a desired gene is flanked by LoxP sites). A second alternative is to perform electroporation in adult mice, as reported (Barnabe-Heider et al., 2008). This approach is technically more challenging and more damaging to the animals since it require use of a stereotactic frame.

It is important to mention one persisting limitation regarding labeling of SVZ astrocytes with any of the above technique. Cells with astrocytic properties in the SVZ are known to be a 


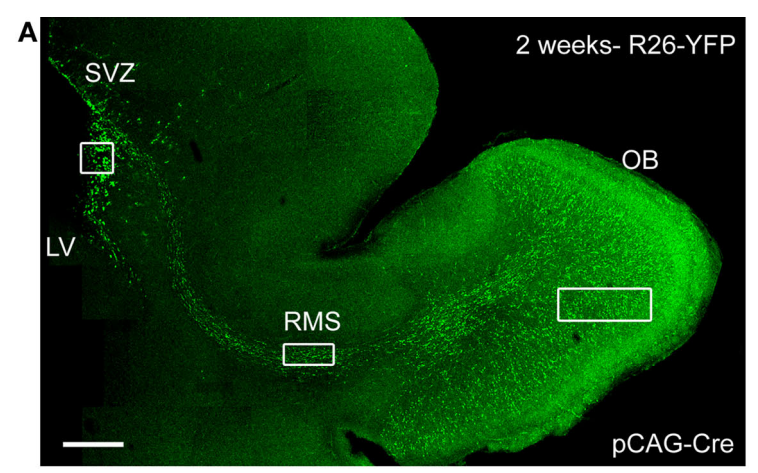

B

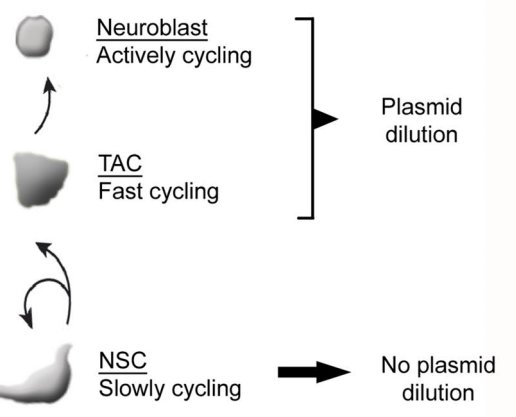

C

First week: $80-90 \%$ colocalization YFP-RFP (०) in R26-YFP
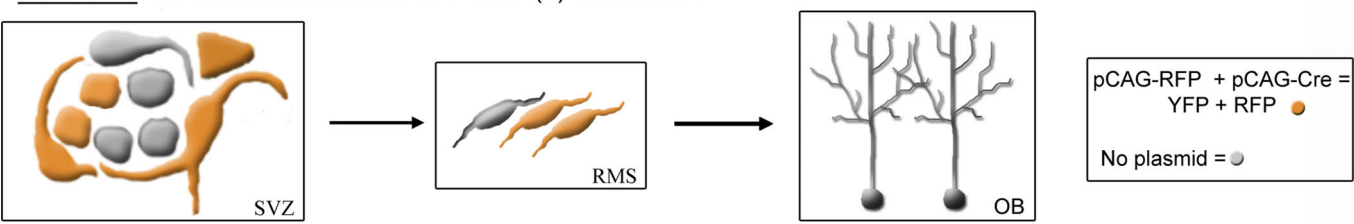

Over time: Dilution of pCAG-RFP (genomic YFP persists)

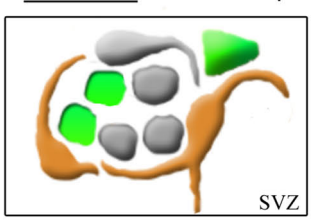

D

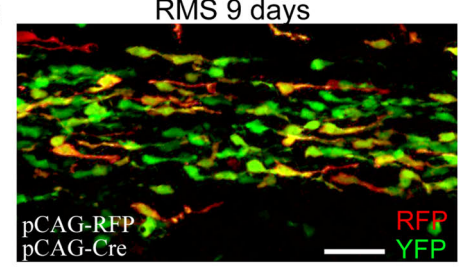

E

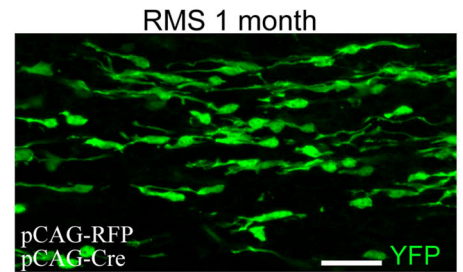

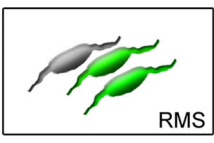

RMS
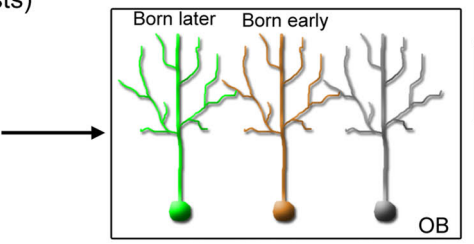

pCAG-Cre $=$ YFP only

$\mathbf{F}$

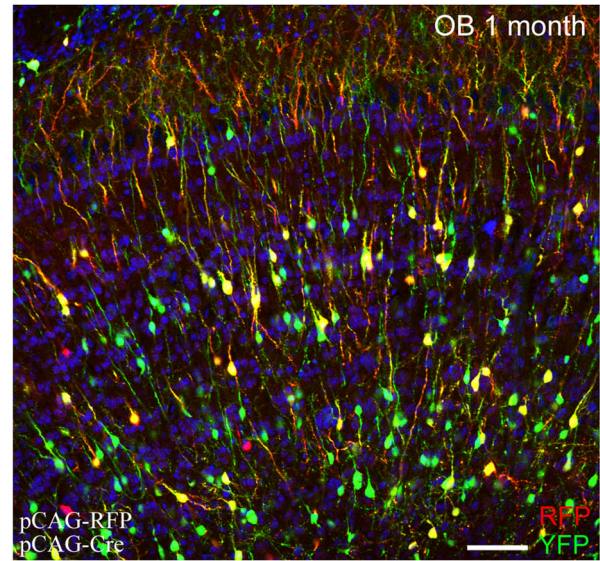

FIGURE 3 | Illustration of plasmid dilution post-electroporation cell but persistent labeling in Rosa mice. (A) Confocal reconstruction of a sagittal section from a 2-week-old R26-YFP mouse in which SVZ cells were electroporated at PO with pCAG-Cre. (B) Diagram illustrating the SVC cell lineage and their plasmid dilution based on their cycling property. (C) Illustration of pCAG-RFP dilution over time occurring in neuroblasts and TACs but not in astrocyte-like cells. Neuroblasts and TACs become green only following PCAG-RFP dilution while astrocyte-like cells express RFP and YFP (orange). YFP is not diluted due to its genomic expression and as a result there will be an accumulation of YFP+ neurons in the OB over time. (D-F) Confocal images of the RMS at 9 days and 1 month ((D) and (E), respectively), and olfactory bulb (OB) at 4 weeks post-electroporation (F) with pCAG-Cre and pCAG-RFP in a Rosa26-Stop-YFP mouse. Scale bars: $200 \mu \mathrm{m}$ (A), $50 \mu \mathrm{m}$ (D) and (E). heterogeneous population: some of these cells will serve as active stem cells while others may act more like astrocytes in other parts of the brain. Additional markers of the true neural progenitor cells/ stem cells are still a matter of debate, limiting our ability to visualize neural progenitor cells in live tissue.

\section{ELECTROPHYSIOLOGY OF SVZ CELLS ACUTE SLICES AND WHOLE MOUNTS}

The preparation of acute slices containing the SVZ and/or RMS has been described in several papers (e.g., Wang et al., 2003a,b; Bolteus et al., 2005) (see additional details in Supplementary Material). 
Here, we discuss the different choices for the plane of sections that are used to address different questions and offer access to different SVZ/RMS regions and cell types. Acute coronal sections provide a good dorsal/ventral view of a SVZ section. These sections tend to be good for immunohistochemical characterization, but because of the heterogeneity of the SVZ along the anterior/posterior axis, this can limit the interpretation of expression pattern to one section. For live sections, this preparation cuts perpendicularly through the migratory path of neuroblasts resulting in a disturbed migration, often resulting in poor SVZ health. In such sections the neuroblasts bulge out of the tissue while astrocytes remain deeper inside the slice (Wang et al., 2003a). Horizontal slices provide good anterior/ posterior view of the SVZ. It is technically advantageous for visual and physical access to ependymal cells (Genzen et al., 2009a,b). Sagittal sections appear to preserve the astrocyte/neuroblast configuration along the anterior/posterior axes best out of the other acute preparations aside from a whole mount. Sagittal sections can vary in terms of the size and region of the SVZ, but can preserve the SVZ/RMS path all the way to the OB.

Whole mounts of the SVZ offer an alternative to the traditional slice preparations (Conover et al., 2000; Platel et al., 2008) (see Supplementary Material). Whole mounts are ideal for preserving the entire integrity of the SVZ, therefore preserving signaling gradients and cell-cell interactions within the region. This preparation allows for visual access to SVZ regions all along the lateral ventricle. One disadvantage is that bath loading of dyes (e.g., calcium indicators) is nearly impossible in this region due to the intact ependymal layer that covers the SVZ and lines the lateral ventricle. As an empirical observation, the ependymal cells tend to take up the calcium indicator dye very well and become fluorescent, masking some of the fluorescence deeper inside the tissue when using a regular confocal microscope. One way around this problem is to use electroporation (see above) prior to whole mount preparation to label cells/introduce calcium indicators in vivo.

\section{ELECTROPHYSIOLOGICAL STUDIES OF SVZ CELLS}

Electrophysiology can be used to reveal the repertoire of channels and receptors in SVZ cells, as it has been applied to mature neurons and astrocytes. Electrophysiological recordings have also provided an ionic signature of SVZ astrocytes and neuroblasts (Wang et al., 2003a; Liu et al., 2005, 2006) (Figure 4). However, due to the size of these cells, the low number of channels in neuroblasts, or the gap junction coupling in SVZ astrocytes, there are technical difficulties that one might face, which are discussed below. Protocols related to patch clamp recordings are provided in the Supplementary Material.

\section{Neuroblast recordings}

The first recordings of neuroblasts were done without knowing the cell identity in acute slices (Figure 4A). The authors suggested that the recorded Lucifer yellow-filled cells were neuroblasts based on their morphology and the fact that the rostral SVZ is composed of $\sim 70 \%$ neuroblasts (Doetsch et al., 1997; Wang et al., 2003a). Later, recorded cells with similar ionic signature were identified as neuroblasts by performing off-line immunostaining for TuJ1 after slice fixation (Bolteus and Bordey, 2004). For acquiring adequate neuroblast recordings and proper interpretation, four technical limitations need to be kept in mind.

First, due to their small soma size, whole-cell patch clamp recordings can quickly lead to cell death in less than $10 \mathrm{~min}$. The cell content is dialized and the cells swell and die. Cell viability has been significantly improved using an ATP-regenerating (creatine-rich) internal solution or performing perforated patch clamp recordings using antibiotics (e.g., gramicidin or amphotericin-B) (Wang et al., 2003b). Perforated patch recordings permit access to the cell without significantly disturbing the internal milieu. Recordings easily last for more than $30 \mathrm{~min}$ up to $90 \mathrm{~min}$. Still, it is difficult to apply perforated patch when recording neuroblasts more than $30 \mu \mathrm{m}$ (i.e., $\sim 4$ cell layer deep) below the surface due to the inability to exert positive pressure to prevent pipette clogging.

Second, neuroblasts express very few channels, which is expected for such small immature cells with high membrane resistance (Wang et al., 2003a). A single NMDA receptor, which has a conductance of $45 \mathrm{pS}$ (i.e., $2.5 \mathrm{pA}$ current at a resting potential of $-55 \mathrm{mV}$ ), would depolarize a $5 \mathrm{G} \Omega$-neuroblasts by $12.5 \mathrm{mV}$. The downside of having so few channels is that they are difficult to detect with electrophysiology as they can be lost in the noise. It is thus required to minimize any electrical noise to detect channels as small as $0.5 \mathrm{pA}$ for GluK5 kainate receptors (Platel et al., 2008).

A third technical issue relates to the accurate measurement of the cell resting potential that was extensively discussed in two previous studies (Wang et al., 2003a,b). The cell resting membrane potential reflects the difference in ionic composition between the inside and outside of the cell. The membrane potential is determined by channels that allow ions in and out. Typically, large cells or neurons contain many channels spread over a larger area. This allows ionic current to flow easily through the cell, meaning the cell has a low resistance. In contrast, neuroblasts are around $6 \mu \mathrm{m}$ in diameter with very few channels. With fewer channels, the resistance of the cell is much higher than neurons. Neuroblasts have resistances in the gigaohm range, about five times higher than large neurons, which have resistances of hundreds of mega-ohms. When one performs patch clamp recordings, one approaches a cell with a glass pipette, applies negative pressure or aspirate, which then brings the membrane in contact with the pipette. This creates a "seal" between the pipette and membrane. Ideally, one would want to form a gigaseal (or a junction between the cell and pipette with a resistance in the giga-ohm range). However, this is still not an ideal junction; there is still a small space between the glass wall of the pipette and the membrane. This space generates an artificial channel that allows some ions (mostly sodium) through. By breaking through the membrane by aspirating sharply to achieve the whole-cell configuration (i.e., when the inside of the pipette is continuous with the cytoplasm of the cell), we have access to the electrical activity in the entire cell. However, the small artificial channel at the cell-pipette junction (i.e., generated by the seal) persists. In a larger neuron with more channels, having this additional small channel has no consequences and is hidden in the noise of the overall reading. However, in smaller cells like SVZ neuroblasts that have very few channels, any additional artificial "channels" prevent an accurate reading of the membrane potential by causing artifactual signals. 


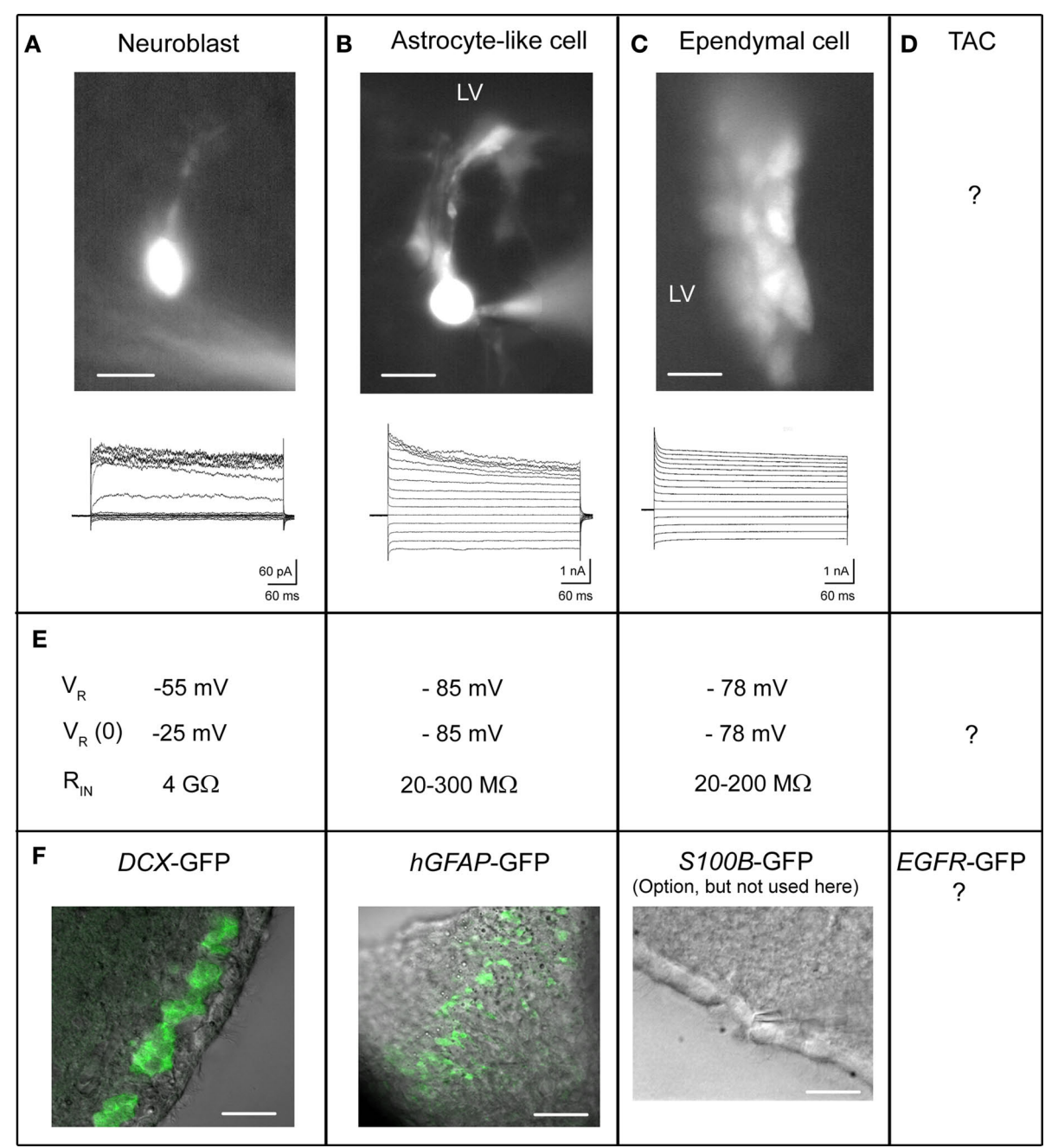

FIGURE 4 | Electrophysiological properties of SVZ cells. (A-D) Each column corresponds to the properties of the following cell type: neuroblasts (A), astrocyte-like cells (B), ependymal cells (C), and the uncharacterizedTAC (D) Live image of Lucifer yellow-filled cells during patch clamp recording are shown for each. (E) Biophysical properties including resting potential $V_{R^{\prime}}$ zero-current $V_{R^{\prime}}$ and input resistance $R_{\mathbb{I N}}$ of the different cell types. (F) Confocal images obtained from transgenic mice DCX-GFP (coronal section) and hGFAP-GFP (sagittal section), and phase image from wild-type mice (horizontal section). Scale bars: $10 \mu \mathrm{m}$ (A, B), $20 \mu \mathrm{M}$ (C), and in (F): $20 \mu \mathrm{m}$ (DCX-GFP), $50 \mu \mathrm{m}$ (hGFAP-GFP), $20 \mu \mathrm{m}$ (phase image).
The positive aspect of a high input resistance is that the voltage clamp of these cells is nearly perfect; there is almost no space-clamp issue, which is inadequate clamp of the voltage of distal processes in large cells or in low input resistance cells.

Finally, a fourth technical issue relates to recording migrating cells as opposed to stationary cells. When recording near physiological temperature, neuroblasts migrate at about 50-60 $\mu \mathrm{m} / \mathrm{h}$ (seven to eight times the cell diameter). The immediate consequence of cell migration is to lose the "seal," meaning to lose the recording. Another consequence is to record artifactual channels due to the imposed stretched or stress on the recorded cell. Indeed, a few minutes prior to "losing the seal," we observe the presence of large channels (20-30 pA) with an increasing frequency. These channels are not observed at room temperature when the cells do not significantly migrate unless there is slice or pipette movement inde- pendent of the cell. We have observed no major differences in ion channel composition in neuroblasts recorded at near-physiological or room temperature.

\section{Astrocyte recordings}

Recordings of SVZ astrocytes have been successfully performed in wild-type mice, but success at recording the proper cell type is enhanced using hGFAP-GFP mice (Liu et al., 2005, 2006) (Figure 4B). In contrast to the high resistance of neuroblasts (around 1-5 G $\Omega$, see explanation for cell resistance above), astrocytes have a low membrane resistance (mean of $30 \mathrm{M} \Omega$, Liu et al., 2006). Astrocytes have many channels open at rest that allow ions (in this case mostly potassium) to flow resulting in a low membrane resistance. Low input resistances can lead to several technical problems for patch clamp recordings. The problem stems 
from the fact that the so-called series resistance, which results from the summated resistances from the pipette, the internal solution, and the seal approximately equal to the membrane resistance (10-50 M $\Omega$, please see some of the basics in the Axon guide ${ }^{3}$ ). As a result the experimenter cannot know whether they are measuring the series or the cell's input resistance. In addition, any changes in the series resistance will affect the electrical reading from the cells. For example, pressure application may lead to changes in series resistance due to changes in the ionic composition around the cells and pipette, in turn leading to changes that could be erroneously interpreted as a response to a drug application.

To partially eliminate this problem we have pharmacologically blocked gap junction coupling, thus increasing membrane resistance of SVZ astrocytes (from 30 to $300 \mathrm{M} \Omega$, Liu et al., 2006). It is important to acknowledge that using a gap junction blocker such as meclofenamic acid is not without side effects as this drug has other actions (e.g. blockade of chloride channels). Other pharmacological agents such as carbenoxolone may be used, with the same caveats in mind. Nevertheless, we believe that using gap junction blockers increases confidence in recordings in being able to separate artifacts from real responses to drugs.

\section{Ependyma recordings}

Recordings of SVZ ependymal cells have been successfully performed in wild-type mice although it may be possible to use $S 100 B$ GFP mice for easier identification of recorded cells as ependymal cells (Figure 4C) Genzen et al. (2009a,b). Finally, there are no published patch clamp data on transient amplifying cells (Figure 4D). Generating EGFR-GFP mice would allow recording such cells.

\section{CALCIUM ACTIVITY IN SVZ CELLS}

Electrophysiology allows us to characterize functional channels and receptors in detail in a single SVZ cell. Calcium imaging, however, allows us to monitor physiological activity in a population of SVZ cells and detect a set of metabotropic receptors. In addition, while neurons communicate through action potential, immature cells communicate through calcium activity and their behavior is calcium dependent. The frequency of calcium activity will define the migratory behavior or the state of proliferation (Komuro and Rakic, 1998; Darcy and Isaacson, 2009). Calcium increase can control the release of neurotransmitters as well as growth factors from SVZ neuroblasts and astrocytes (Liu et al., 2005; Platel et al., 2010). Calcium, and in particular the information encoded in its activity pattern, define the stages of a cell development and its means of communication with surrounding cells (Spitzer, 2006). Here, we discuss considerations of calcium dye selection, calcium dye loading protocols, temperature considerations, and other considerations. The protocols are provided as Supplementary Material.

\section{CALCIUM DYE SELECTION}

Several calcium indictor dyes are commercially available with different calcium binding properties and fluorescence upon calcium binding. The calcium dyes can be classified by their excitation/ emission spectra. Fluo-4 AM and Oregon Green BAPTA-1 AM are "green dyes" that are excited most efficiently in single-photon

${ }^{3}$ moleculardevices.com/pages/instruments/axon_guide.html excitation by a $488 \mathrm{~nm}$ laser and emit approximately at $500-550 \mathrm{~nm}$ (Figures 6A,B); "red dyes" (e.g., Rhod-2, Figure 6C) are excited by a $543 \mathrm{~nm}$ laser and emit at 575-625 nm and are thus less toxic for long term imaging. However, red dyes exhibited a lower dynamic range than green dyes (i.e., lower fluorescence change for a similar calcium concentration change) or had a unreliable baseline loading in our system (data not shown). Among the green dyes excited by a $488 \mathrm{~nm}$ laser, we favor Fluo-4 AM compared to Oregon Green BAPTA-1 AM. Although Oregon Green has higher baseline fluorescence than Fluo-4 AM (and cells are more obviously loaded), the latter has greater sensitivity to calcium concentration changes than Oregon Green. In other words, at a given level of calcium binding, a greater change in fluorescence is observed with Fluo-4 AM compared to Oregon Green (Figure 6).

\section{IDENTIFYING SPECIFIC CELL POPULATIONS DURING CALCIUM IMAGING}

One challenge when studying the SVZ in live slices is cell type identification. As described above, transgenic mice and in vivo electroporation facilitates the identification of cell types using cell-type specific markers. We have also discovered that different methods of calcium dye loading result in preferential loading of certain populations of SVZ cells as detailed below and illustrated in Figure 5.

\section{Bath loading or surface loading of calcium dye for neuroblast labeling} Bath loading of Fluo-4 AM labels neuroblasts preferentially (Figures 5A,B). This can be corroborated by loading in transgenic mice that labels cell-specific markers (positive-staining in DCX-marked cells, negative loading in GFAP-marked cells, see below) noting the morphology of the cell, or observing migration of cells with calcium activity ( since astrocytes do not migrate, Platel et al., 2009). Confocal image stacks of the Fluo-4 channel and DIC channel reveals that some cells, presumably astrocytes, are not well labeled or are only occasionally labeled. At the technical level, slices are incubated with the dye $(4-10 \mu \mathrm{M})$ for $30-45 \mathrm{~min}$ at room temperature with bubbled oxygen or at physiological temperature in a gas- and temperature-controlled incubator. Next, a de-esterification step occurs when slices are returned to a bubbled ACSF for at least 30 min (Figures 5A,B).

A second method to preferentially label neuroblasts is to pressure apply a higher concentration of the calcium dye on the slice surface (Figures 5B,C). This method has the advantage of labeling a slice faster since the loading period is significantly reduced from $30-45 \mathrm{~min}$ to $2-3 \mathrm{~min}$. A pressure pipette is prepared by filling with $250 \mu \mathrm{M}$ of Fluo- 4 AM.

Both methods can be used for identifying receptor expression. However, because the slice integrity is not well preserved at the surface, this method is not ideal for recording spontaneous calcium activity because signaling molecules can be carried away by the bath perfusion system.

\section{Pressure loading of calcium dye for astrocyte labeling}

Pressure application deep in the slice preferentially labels astrocytes in the SVZ. The cell morphology characterized by processes projecting onto blood vessels or loading in $h G F A P$-driven transgenic mice strongly suggests astrocyte-specific labeling (see above and next paragraph). Although many neuroblasts are loaded, their baseline and spontaneous fluorescence changes are lower 


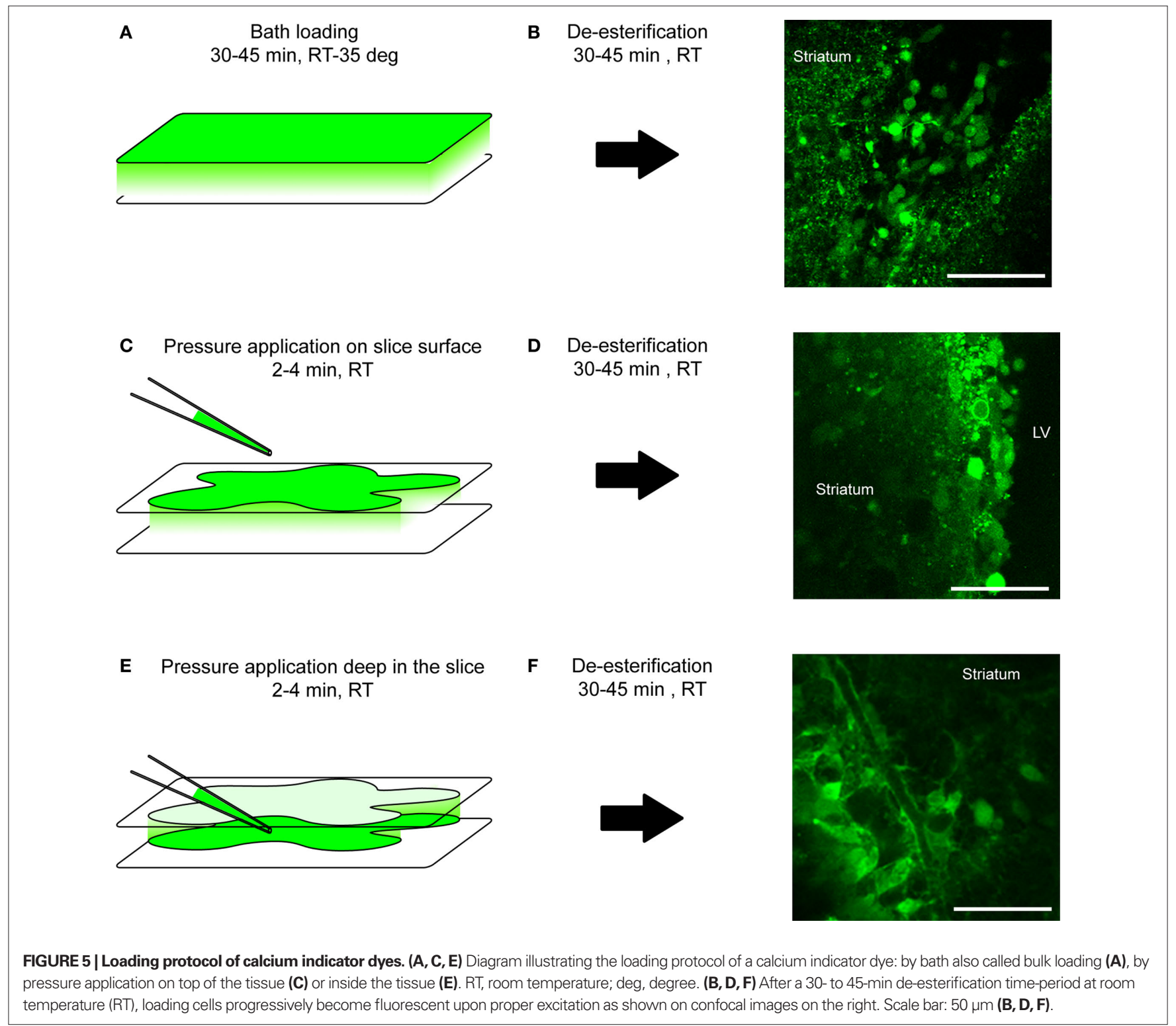

than in astrocytes. This is presumably due to the fact that neuroblasts are tightly packed and further ensheathed by astrocytes and sufficient dye diffusion into the neuroblast clusters is more difficult. However, with a strong agonist application, cells other than astrocytes (presumably neuroblasts) show obvious calcium changes in the SVZ (Figure 6G). Technically, after identifying the area of interest and focus plane, the tip of a pressure pipette filled with $250 \mu \mathrm{M}$ of Fluo-4 AM is placed $50-100 \mu \mathrm{m}$ below the focus plane since the dye diffuses towards the surface. In addition, the pipette is placed approximately $\sim 100 \mu \mathrm{m}$ away from the SVZ in the XY-plane to minimize mechanical distortion of the tissue during pressure application. To further minimize mechanical distortion of the tissue, we apply at a pressure of 1-3 PSI, just enough to observe that the solution is being ejected from the pipette. The duration of application is at least $2 \mathrm{~min}$ but can be repeated if the signal is low after one application. The signal intensity due to progressive de-esterification of the AM dye increases with time and peaks around $30-45 \mathrm{~min}$. The waiting time during de-esterification also allows the slice to recover from possible mechanical distortion during loading (Figures 5C-F).

\section{CALCIUM IMAGING IN TRANSGENIC MICE OR GENETICALLY-ENCODED CALCIUM SENSOR}

The cell type selectivity of the different dye loading protocols described above are corroborated by and used in combination with transgenic mice (Figure 6). In acute slices, Fluo-4 AM dye has been a reliable and adequate sensor for monitoring calcium activity in astrocytes, ependymal cells and neuroblasts (Platel et al., 2007b, 2008, 2010; Genzen et al., 2009a; Young et al., 2010). To image calcium activity in SVZ astrocytes, we prefer using $h$ GFAPMrgA1:GFP transgenic mice. While the fluorescence emission of Fluo-4 AM overlaps with GFP, it is still possible to identify calcium activity in GFP-positive cells (i.e., astrocytes) for the following two reasons: (1) MrgA1 is a membrane-bound receptor so it is possible 


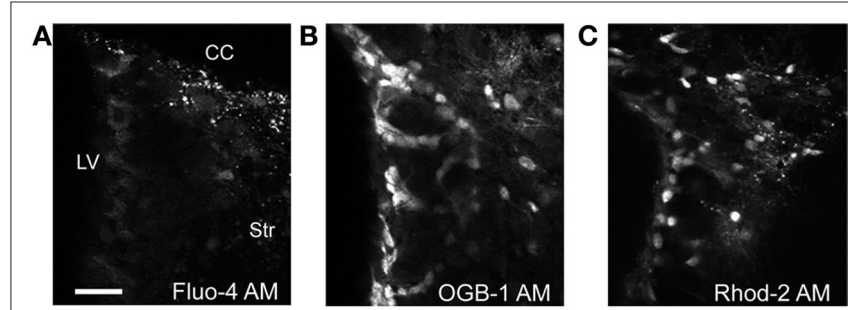

Muscimol $50 \mu \mathrm{M}$

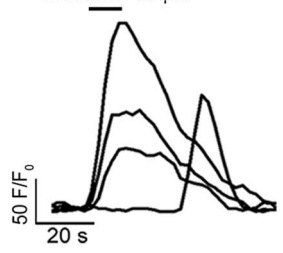

-
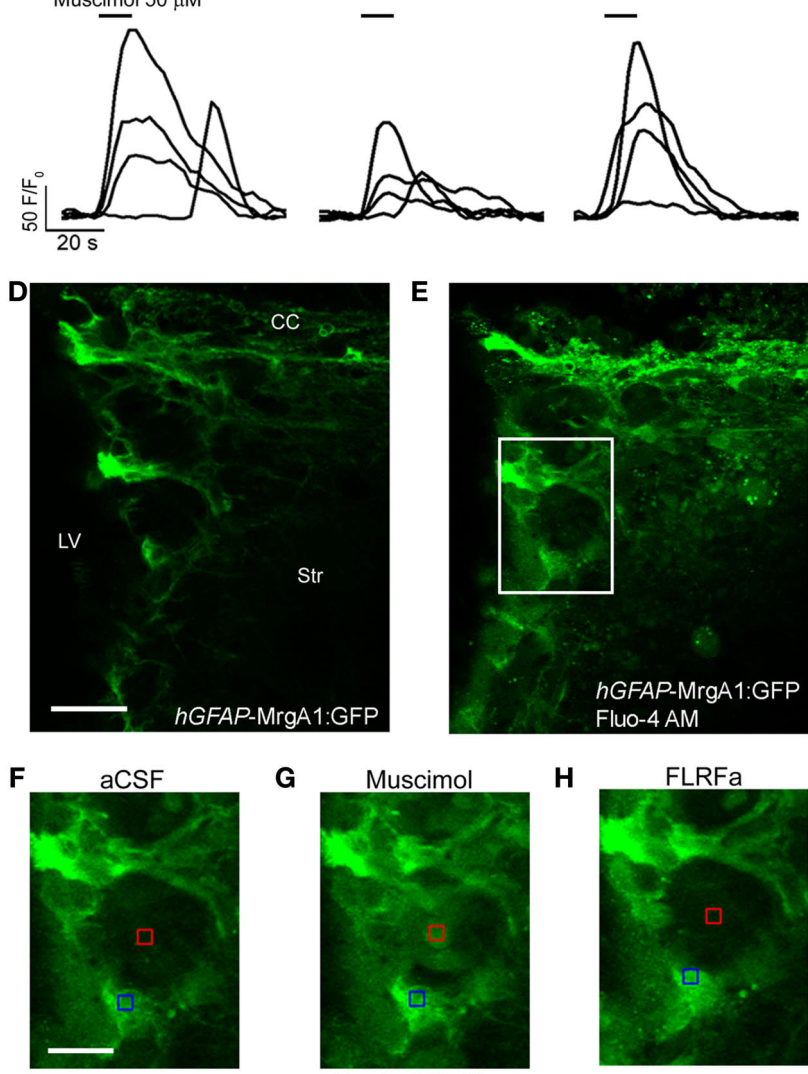

G

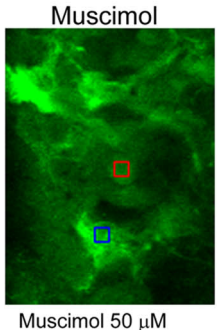

H

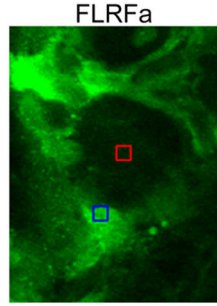

Muscimol $50 \mu \mathrm{M}$
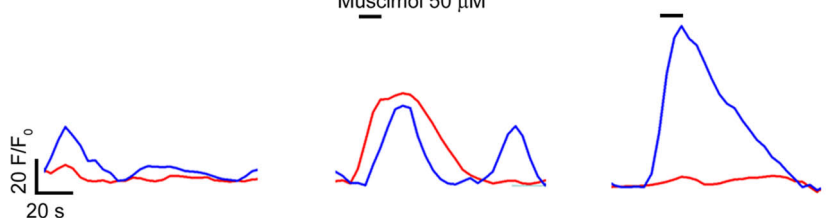

FIGURE 6 | Calcium imaging with different dyes and in transgenic mice.

(A-C) Confocal images displaying SVZ cells loaded with Fluo-4 AM (A), Oregon Green BAPTA-1 AM (OGB-1 AM) (B), Rhod-2 AM (C) with

corresponding muscimol-induced calcium responses under each image. (D, E) Confocal images of SVZ cells before (D) and after (E) Fluo-4 AM loading in a sagittal section from a hGFAP-MrgA1:GFP mouse. (F-H) Zoomed images from the white box shown in (D) and (E), before (F) and during muscimol (G) or FLRFa (H) application. CC, corpus callosum; LV, lateral ventricle; Str, striatum. Scale bars: $30 \mu \mathrm{m}$ (A-C), $30 \mu \mathrm{m}$ (D, E), $15 \mu \mathrm{m}$ (F-H).

to distinguish astrocytes by the membrane-lined green fluorescence prior to and even following Fluo-4 AM loading and (2) a selective agonist of the MrgA1 receptor (the phe-leu-arg-phe amide peptide, FLRFa) can be used to increase $\mathrm{Ca}^{2+}$ in GFP-fluorescent cells allowing further identification of the FLRFa-responding cells as astrocytes at the end of each experiment. For neuroblasts, we recommend using $D C X$-DsRed mice. DsRed fluorescence does not overlap with Fluo-4 fluorescence allowing unambiguous identification of the imaged DsRed-fluroescent cells as neuroblasts. Another mouse line of interest is the Cre-electroporated Rosa26-Stop-tdTomato mice. One or 2 months post-electroporation, neuroblasts can be selectively imaged in the RMS where radial glia/astrocytes are not electroporated and thus do not express tdTomato.

A recent study reported the use of the genetic calcium sensor GCAMP2 (Chesler et al., 2008). GCamp2 is a circularly permutated EGFP/M13/calmodulin (CaM) fusion protein, the fluorescence of which is calcium-sensitive (for review see Mank and Griesbeck, 2008). GCamp2 can be easily electroporated into SVZ cells during the neonatal period. However, due to dilution at 1-2 month postelectroporation, only SVZ astrocytes, ependymal cells, and neurons integrating into the $\mathrm{OB}$ will express GCamp2. Nevertheless, it should be feasible to study calcium activity in migrating neuroblasts for 1-3 weeks post-electroporation. A new version of the GCamp2 sensor, GCamp3, with enhanced changed in fluorescence is available allowing higher sensitivity and higher baseline fluorescence (Tian et al., 2009). These sensors will become important when monitoring calcium activity in vivo.

\section{ACQUISITION METHOD: CCD CAMERA ACOUISITION VERSUS CONFOCAL MICROSCOPY}

To detect emission of calcium-sensitive dye, we have used a chargecoupled device (CCD) camera or confocal microscopy. Both have distinct limitations and benefits, mainly concerning spatial and temporal resolution. CCD cameras have at least two advantages over confocal microscopy. First, they can acquire images approximately 10-100 times faster than confocal scanning microscopes for the same field of view. Second, epifluorescence is less damaging than confocal microscopy. The main advantage of confocal microscopy is spatial resolution. While having a smaller aperture can be considered a limitation if the desire is to image more cells in the Z-plane (depth), the trade-off is much greater spatial resolution in the XY-plane compared to CCD camera-based acquisition. This allows activity to be detected in single cells and their processes without emission contamination from cells above or below. This is particularly important for a region like the SVZ where cells are tightly packed together.

\section{ANALYSIS OF CALCIUM ACTIVITY DATA}

There are several programs available from companies that sell equipment for calcium imaging. We have used Dr. J. C. Platel's custom-written software, CalSignal, which allows automatic detection and tracking of the cells (Platel et al., 2007a). Data (fluorescence values) obtained using CalSignal are then exported into Clampfit (PClamp 10, Molecular Devices) to be treated as synaptic currents to obtain information about rise time, amplitude, area, and frequency. In particular, we use the threshold detection function of Clampfit. A manual or automatic baseline adjustment can also be used to visualize all the traces in the same windows.

\section{MIGRATION OF SVZ/RMS NEUROBLASTS}

The study of cell migration faced two challenges: cell labeling and technical problems associated with drifts and data analysis. At first, intraventricular injections of dyes such as Cell Tracker Green 
(De Marchis et al., 2001) or dioleyl-tetramethylindocarbocyanine methanesulfonate DiI (Doetsch and Alvarez-Buylla, 1996) have allowed experimenters to label SVZ cells and thus visualize neuroblasts along their route to the OB. DiI was also directly applied on organotypic slices to acutely label cells in the SVZ or RMS and followed their migration for several hours (Murase and Horwitz, 2002). This method avoids using stereotactic injections of dye into the ventricle, but relies on rather difficult placement of the dye (personal observation). Another approach is to use transgenic mice to selectively visualize neuroblasts (see Table 1). We and others imaged neuroblast migration in acute slices and whole mounts using DCX-GFP mice among others (Nam et al., 2007; Platel et al., 2008; Kim et al., 2009) (see Imaging Cell Migration in the Supplementary Material). However, the density of neuroblasts is so high that individual cells are difficult to track. Using these mice required the use of confocal microscopy. Dr. Szele's lab used GAD-65 mice allowing a subset of neuroblasts to be visualized (Nam et al., 2007). We favor using neonatal electroporation in Rosa26-Stop-tdTomato mice and electroporation of a pCAG-Cre vector (Platel et al., 2010) (Figure 7). As detailed above, a subset of neuroblasts are tdTomato-fluorescent allowing easy visualization and tracking of individual cells (Figure 7). This approach has

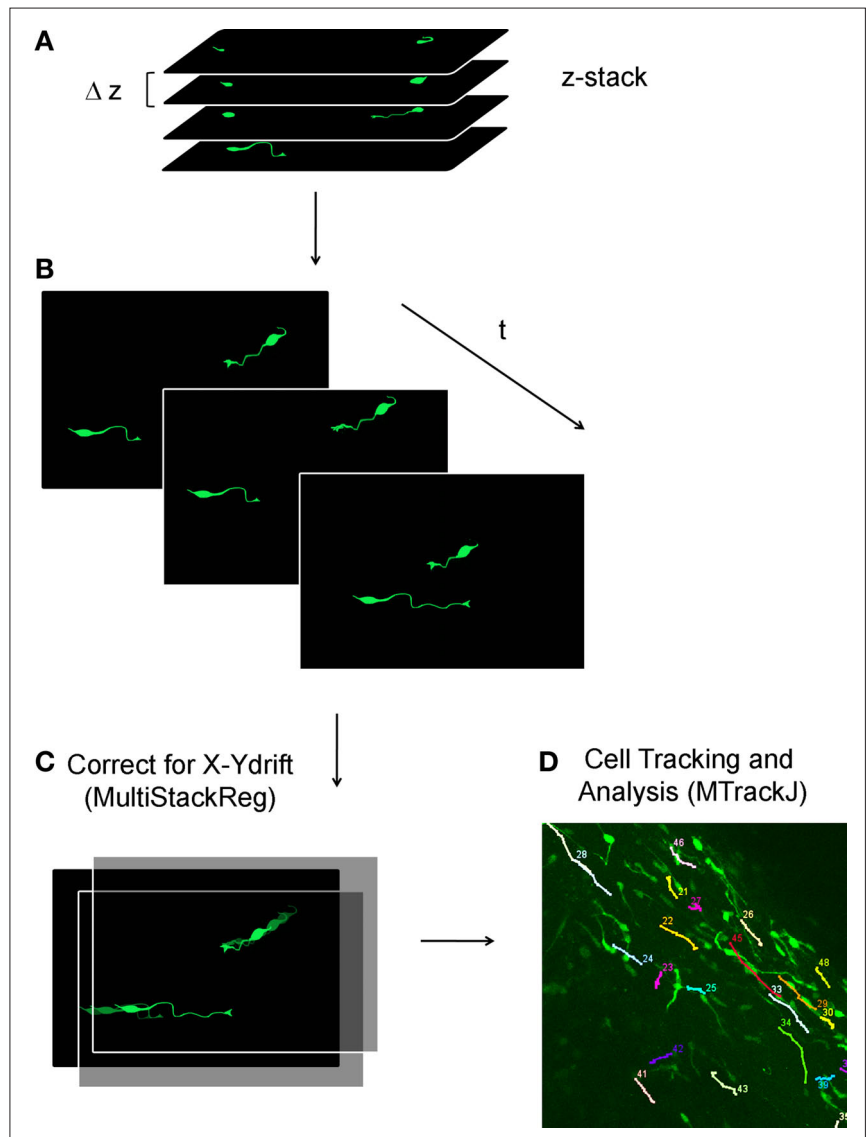

FIGURE 7 |Analysis of neuroblast migration in acute sagittal slices. (A, B) Schematic of a confocal Z-stacks spaced by $1-2 \mu \mathrm{m}$ (A) are acquired every 5-15 min (B). (C) Off-line, the reconstructed movies are corrected for $X-Y$ drift using MultiStackReg ImageJ Plugin (NIH ImageJ). (D) Cell tracking and migration analysis is performed using MTrackJ ImageJ Plugin. several advantages: (1) tdTomato is excited with a $543 \mathrm{~nm}$ laser, which is less toxic for cells than a $488 \mathrm{~nm}$ laser. (2) Because only a subset of neuroblasts are red fluorescent and tdTomato is the brightest red protein, we can now use a CCD camera to track cell migration at much higher speeds and for longer period of time due to the reduction of toxicity. (3) This approach can be combined with calcium imaging using a green fluorescent calcium indicator (e.g., Fluo-4). (4) RNA interference, overexpression vector, or Cre recombinase in floxed mice can be expressed in cells allowing the experimenter to analyze the effect of genetic manipulation on cell migration.

At the technical level, migration movies were acquired at $37^{\circ} \mathrm{C}$ with a Super $20 \times$ objective (NA 0.95, Olympus) allowing a large field of view. Using confocal microscopy, it is necessary to acquire several optical sections every $5-15 \mathrm{~min}$ (i.e., Z-stacks over 50-100 $\mu \mathrm{m}$, Figures 7A,B). Because there is often drift at higher temperatures, it is also necessary to realign the movie on-line in the $\mathrm{Z}$-axis through manual focus adjustment. With the use of ImageJ plug-ins, image stacks can be realigned in the XY-plane (Stackreg, Thevenaz et al., 1998; Figure 7C) and the migratory behavior of YFP-fluorescent cells can be tracked and analyzed (MTrackJ written by Dr. E. Meijering, Biomedical Imaging Group Rotterdam, Figure 7D).

\section{ADDITIONAL TECHNICAL CONSIDERATIONS}

There are some considerations for recording or imaging related to the age of mice and the depth of recording. During the neonatal period, the SVZ display important structural and cellular changes. The neonatal period displays both neurogenesis and gliogenesis (Marshall et al., 2003). During the neonatal period, radial glia generate both neuroblasts and glioblasts. Gliogenesis (and in particular glioblast fate and migration) has been studied using viral labeling and time-lapse microscopy (Levison et al., 1993; Kakita and Goldman, 1999). Using electroporation of Rosa26 reporter mice or electroporation of a GFP-encoding plasmid will result in labeling of both glioblasts and neuroblasts. This is a limitation when one wants to selectively study the migration of one cell population. An alternative is to use either the different lines of transgenic mice or a plasmid encoding Cre or GFP under a neuronal or glial promoter. During the neonatal period, radial glia progressively transform into ependymal cells and astrocytes including SVZ astrocytes (Merkle et al., 2004). This results in important structural changes such as a progressive ensheathment of the chains of migrating neuroblasts by astrocytes, the formation of several chains instead of one main large chain, and a reduction of the size of the SVZ over time (Law et al., 1999; Peretto et al., 2005). The adult SVZ and RMS display an organized migration in chains while the neonatal tissue may be less organized. The presence of tight chains or clusters of neuroblasts is, however, less permissive to calcium dye penetration resulting in the need for developing additional loading protocols (see above).

Perhaps the greatest challenge when using young adult or adult tissue is to preserve the viability of the tissue, in particular the parenchymal tissue surrounding the SVZ. Great care such as using sucrose-based slicing solution to limit neuronal excitability or cooler slicing conditions is necessary. Another challenge in using adult tissue is the mode of cell labeling when one cannot use transgenic reporter mouse lines. More specifically, injecting dye or 
electroporating in neonates is simple and does not require surgery or stereotactic instruments. Neonatal electroporation has been attractive for us because it allows labeling cells at postnatal day 1 for analyzing their migration at different time points thereafter in Rosa26 reporter mice.

A technical challenge for both electrophysiology and imaging (calcium or migration) is to image deep inside the tissue where the integrity of the SVZ is better preserved. The top of the slice is often damaged due to the presence of dying cells oxygen radical formation. In addition, the surface is considerably disorganized and does not display chain migration. It is thus important to record or image cells at a minimum of three to four cell layers deep. To penetrate the SVZ tissue with a patch pipette we apply a small positive pressure at the tip of the pipette. We can visualize clusters of neuroblasts and avoid them while pushing the pipette through the tissue. Using fluorescent reporter mice or GFP-tagged cells allows us to image and record relatively deep (at least $50 \mu \mathrm{m}$ below the surface).

An approach that we did not discuss above is using slice culture for addressing many questions related to cell migration, differentiation, integration into a circuit, or even testing cell transplant efficiency. We will refer to a recent article by Tanvig et al. (2009) that presents some of the advantages of organotypic sagittal slices containing the entire SVZ-to-OB axis.

\section{CONCLUSIONS}

Over the past several years, several approaches to unambiguously identify every cell type in the SVZ have been developed. In particular, the generation of new lines of transgenic mice expressing GFP or RFP under selective cell-specific promoters has become helpful. In addition, using in vivo electroporation in neonatal fluorescence reporter mice (e.g., Rosa26-Stop-tdTomato) will make studying cell migration and calcium activity accessible to many labs. Calcium activity can be easily monitored with either classical organic calcium indicators or genetic calcium sensors along with confocal microscopy or CCD cameras. One important aspect of the in vivo electroporation is allowing us to genetically modify the system as was reported with viral vectors. Using floxed mice will allow investigators to remove the floxed gene in stem cells. In addition, vectors encoding short hairpin RNA (shRNA) or overexpression vectors can be easily introduced into SVZ cells. However, one important limitation of neonatal electroporation is the dilution of plasmid limiting RNAi expression in cells born during the neonatal period. We are hopeful that combining this technology with the use of vectors encoding transposons for example will permit genetic integration of the gene of interest in neural progenitor cells (Sato et al., 2007). Alternatively, electroporation can be used in adults as is shown for viral vector injection. In conclusion, we hope to have provided some insights on the diverse approaches to study the electrophysiology, migration, and calcium activity in SVZ cells under control conditions or following genetic manipulations.

\section{ACKNOWLEDGMENTS}

Thisworkwassupported bygrantsfrom theNIH(NS042189,NS048256, and DC007681, Angélique Bordey; NRSA, Stephanie Z. Young), Pardee Foundation (Angélique Bordey), National Science Foundation (Benjamin Lacar), and TS Alliance (Jean-Claude Platel).

\section{SUPPLEMENTARY MATERIAL}

The Supplementary Material for this article can be found online at http://www.frontiersin.org/neuroscience/neurogenesis/ paper/10.3389/fnins.2010.00043/

\section{REFERENCES}

Aguirre, A., and Gallo, V.(2004). Postnatal neurogenesis and gliogenesis in the olfactory bulb from NG2-expressing progenitors of the subventricular zone. J. Neurosci. 24, 10530-10541.

Aguirre, A.A., Chittajallu. R., Belachew, S., and Gallo, V. (2004). NG2-expressing cells in the subventricular zone are type C-like cells and contribute to interneuron generation in the postnatal hippocampus. J. Cell Biol. 165, 575-589.

Akli, S., Caillaud, C., Vigne, E., StratfordPerricaudet, L. D., Poenaru, L., Perricaudet, M., Kahn, A., and Peschanski, M. R. (1993). Transfer of a foreign gene into the brain using adenovirus vectors. Nat. Genet. 3, 224-228.

Altman, J. (1963). Autoradiographic investigation of cell proliferation in the brains of rats and cats. Anat. Rec. $145,573-591$.

Altman, J. (1969). Autoradiographic and histological studies of postnatal neurogenesis. IV. Cell proliferation and migration in the anterior forebrain, with special reference to persisting neurogenesis in the olfactory bulb. J. Comp. Neurol. 137, 433-457.

Attardo, A., Calegari, F., Haubensak, W., Wilsch-Brauninger, M., and Huttner, W. B. (2008). Live imaging at the onset of cortical neurogenesis reveals differential appearance of the neuronal phenotype in apical versus basal progenitor progeny. PLoS ONE 3, e2388. doi: 10.1371/journal. pone.0002388.

Balordi, F., and Fishell, G. (2007). Hedgehog signaling in the subventricular zone is required for both the maintenance of stem cells and the migration of newborn neurons. $J$. Neurosci. 27, 5936-5947.

Barnabe-Heider, F., Meletis, K., Eriksson, M., Bergmann, O., Sabelstrom, H., Harvey, M.A., Mikkers, H., and Frisen, J. (2008). Genetic manipulation of adult mouse neurogenic niches by in vivo electroporation. Nat. Methods 5, 189-196.

Betz, U. A., Vosshenrich, C. A., Rajewsky, K., and Muller, W. (1996). Bypass of lethality with mosaic mice generated by Cre-loxP-mediated recombination. Curr. Biol. 6, 1307-1316.

Blakemore, W. F. (1969). The ultrastructure of the subependymal plate in the rat. J. Anat. 104, 423-433.

Bolteus, A. J., and Bordey, A. (2004). GABA release and uptake regulate neuronal precursor migration in the postnatal subventricular zone. J. Neurosci. 24 7623-7631.

Bolteus, A. J., Garganta, C., and Bordey, A. (2005). Assays for measuring extracellular GABA levels and cell migration rate in acute slices. Brain Res. Brain Res. Protoc. 14, 126-134.

Boutin, C., Diestel, S., Desoeuvre, A. Tiveron, M. C., and Cremer, H. (2008). Efficient in vivo electroporation of the postnatal rodent forebrain. PLoS ONE 3, e1883. doi: 10.1371/journal. pone.0001883.

Braun, N., Sevigny, J., Mishra, S. K., Robson, S.C., Barth, S.W., Gerstberger, R., Hammer, K., and Zimmermann, H. (2003). Expression of the ecto-ATPase NTPDase 2 in the germinal zones of the developing and adult rat brain. Eur. J. Neurosci. 17, 1355-1364.
Brill, M. S., Ninkovic, J., Winpenny, E., Hodge, R. D., Ozen, I., Yang, R., Lepier, A., Gascon, S., Erdelyi, F., Szabo, G., Parras, C., Guillemot, F., Frotscher, M. Berninger, B., Hevner, R. F., Raineteau, O., and Gotz, M. (2009). Adult generation of glutamatergic olfactory bulb interneurons. Nat. Neurosci. 12, 1524-1533.

Carlen, M., Meletis, K., Barnabe-Heider, F., and Frisen, J. (2006). Genetic visualization of neurogenesis. Exp. Cell Res. 312, 2851-2859.

Cesetti, T., Obernier, K., Bengtson, C. P., Fila, T., Mandl, C., Holzl-Wenig, G., Worner, K., Eckstein, V., and Ciccolini, F. (2009). Analysis of stem cell lineage progression in the neonatal subventricular zone identifies EGFR+/NG2cells as transit-amplifying precursors. Stem Cells 27, 1443-1454.

Chesler, A. T., Le Pichon, C. E., Brann, J. H., Araneda, R. C., Zou, D. J., and Firestein, S. (2008). Selective gene expression by postnatal electroporation during olfactory interneuron neurogenesis. PLoS ONE3, e1517. doi: 10.1371/journal.pone.0001517. 
Conover,J.C., Doetsch, F., Garcia-Verdugo, J. M., Gale, N. W., Yancopoulos, G. D., and Alvarez-Buylla, A. (2000). Disruption of Eph/ephrin signaling affects migration and proliferation in the adult subventricular zone. Nat. Neurosci. 3, 1091-1097.

Darcy, D. P., and Isaacson, J. S. (2009). L-Type calcium channels govern calcium signaling in migrating newborn neurons in the postnatal olfactory bulb. J. Neurosci. 29, 2510-2518.

Davidson, B. L., Allen, E. D., Kozarsky, K. F., Wilson, J. M., and Roessler, B. J. (1993). A model system for in vivo gene transfer into the central nervous system using an adenoviral vector. Nat. Genet. 3, 219-223.

De Marchis, S., Fasolo, A., Shipley, M., and Puche, A. (2001). Unique neuronal tracers show migration and differentiation of SVZ progenitors in organotypic slices. J. Neurobiol. 49, 326-338.

De Marchis, S., Temoney, S., Erdelyi, F., Bovetti, S., Bovolin, P., Szabo, G., and Puche, A. C. (2004). GABAergic phenotypic differentiation of a subpopulation of subventricular derived migrating progenitors. Eur. J. Neurosci. 20, 1307-1317.

Doetsch, F., and Alvarez-Buylla, A. (1996). Network of tangential pathways for neuronal migration in adult mammalian brain. Proc. Natl. Acad. Sci. U.S.A. 93, 14895-14900.

Doetsch, F., Caille, I., Lim, D. A., GarciaVerdugo, J. M., and Alvarez-Buylla, A. (1999). Subventricular zone astrocytes are neural stem cells in the adult mammalian brain. Cell 97, 703-716.

Doetsch, F., Garcia-Verdugo, J. M., and Alvarez-Buylla, A. (1997). Cellular composition and three-dimensional organization of the subventricular germinal zone in the adult mammalian brain. J. Neurosci. 17, 5046-5061.

Feng, L., Hatten, M. E., and Heintz, N. (1994). Brain lipid-binding protein (BLBP): a novel signaling system in the developing mammalian CNS. Neuron 12, 895-908.

Fiacco, T. A., Agulhon, C., Taves, S. R., Petravicz, J., Casper, K. B., Dong, X., Chen, J., and McCarthy, K. D. (2007). Selective stimulation of astrocyte calcium in situ does not affect neuronal excitatory synaptic activity. Neuron 54, 611-626.

Ganat, Y. M., Silbereis, J., Cave, C., Ngu, H., Anderson, G. M., Ohkubo, Y., Ment, L. R., and Vaccarino, F. M. (2006). Early postnatal astroglial cells produce multilineage precursors and neural stem cells in vivo. J. Neurosci. 26, 8609-8621.

Genzen, J. R., Platel, J. C., Rubio, M. E., and Bordey, A. (2009a). Ependymal cells along the lateral ventricle express functional $\mathrm{P} 2 \mathrm{X}(7)$ receptors. Purinergic Signal. 5, 299-307.

Genzen, J. R., Yang, D., Ravid, K., and Bordey, A. (2009b). Activation of adenosine $\mathrm{A} 2 \mathrm{~B}$ receptors enhances ciliary beat frequency in mouse lateral ventricle ependymal cells. Cerebrospinal Fluid Res. 6, 15.

Goings, G. E., Kozlowski, D. A., and Szele, F. G. (2006). Differential activation of microglia in neurogenic versus nonneurogenic regions of the forebrain. Glia 54, 329-342.

Hockfield, S., and McKay, R. D. (1985). Identification of major cell classes in the developing mammalian nervous system. J. Neurosci. 5, 3310-3328.

Isaka, F., Ishibashi, M., Taki, W., Hashimoto, N., Nakanishi, S., and Kageyama, R. (1999). Ectopic expression of the bHLH gene Math1 disturbs neural development. Eur. J. Neurosci. 11, 2582-2588.

Jankovski, A., and Sotelo, C. (1996). Subventricular zone-olfactory bulb migratory pathway in the adult mouse: cellular composition and specificity as determined by heterochronic and heterotopic transplantation. J. Comp. Neurol. 371, 376-396.

Johansson, C. B., Lothian, C., Molin, M., Okano, H., and Lendahl, U. (2002). Nestin enhancer requirements for expression in normal and injured adult CNS. J. Neurosci. Res. 69, 784-794.

Jung, S., Aliberti, J., Graemmel, P., Sunshine, M. J., Kreutzberg, G. W., Sher, A., and Littman, D. R. (2000). Analysis of fractalkine receptor CX(3) CR1 function by targeted deletion and green fluorescent protein reporter gene insertion. Mol. Cell Biol. 20, 4106-4114.

Kakita, A., and Goldman, J. E. (1999). Patterns and dynamics of SVZ cell migration in the postnatal forebrain: monitoring living progenitors in slice preparations. Neuron 23, 461-472.

Kane, N. M., McRae, S., Denning, C., and Baker,A.H. (2008). Viral and non-viral gene delivery and its role in pluripotent stem cell engineering. Drug Discov Today Technol. 5, e107-e115.

Kim, Y., Comte, I., Szabo, G., Hockberger, P., and Szele, F. G. (2009). Adult mouse subventricular zone stem and progenitor cells are sessile and epidermal growth factor receptor negatively regulates neuroblast migration. PLoS ONE 4, e8122. doi: 10.1371/journal. pone.0008122

Kishi, K. (1987). Golgi studies on the development of granule cells of the rat olfactory bulb with reference to migration in the subependymal layer. J. Comp. Neurol. 258, 112-124.

Komitova, M., Zhu, X., Serwanski, D. R., and Nishiyama, A. (2009). NG2 cells are distinct from neurogenic cells in the postnatal mouse subventricular zone. J. Comp. Neurol. 512, 702-716.

Komuro, H., and Rakic, P. (1998). Orchestration of neuronal migration by activity of ion channels, neurotransmitter receptors, and intracellular Ca2+ fluctuations. J. Neurobiol. $37,110-130$.

Kuzmanovic, M., Dudley, V. J., and Sarthy, V. P. (2003). GFAP promoter drives Muller cell-specific expression in transgenic mice. Invest. Ophthalmol. Vis. Sci. 44, 3606-3613.

Lagace, D. C., Whitman, M. C., Noonan, M. A., Ables, J. L., DeCarolis, N. A., Arguello, A. A., Donovan, M. H., Fischer, S. J., Farnbauch, L. A. Beech, R. D., DiLeone, R. J., Greer, C. A., Mandyam, C. D., and Eisch, A. J. (2007). Dynamic contribution of nestin-expressing stem cells to adult neurogenesis. J. Neurosci. 27 12623-12629.

Law, A. K., Pencea, V., Buck, C. R., and Luskin, M. B. (1999). Neurogenesis and neuronal migration in the neonatal rat forebrain anterior subventricular zone do not require GFAP-positive astrocytes. Dev. Biol. 216, 622-634.

Le Gal, L. S., Robert, J. J., Berrard, S., Ridoux, V., Stratford-Perricaudet, L. D., Perricaudet, M., and Mallet, J. (1993). An adenovirus vector for gene transfer into neurons and glia in the brain. Science 259, 988-990.

Levison, S. W., Chuang, C., Abramson, B. J., Goldman, J. E. (1993). The migrational patterns and developmental fates of glial precursors in the rat subventricular zone are temporally regulated. Development 119, 611-622.

Levison, S. W., and Goldman, J. E. (1993). Both oligodendrocytes and astrocytes develop from progenitors in the subventricular zone of postnatal rat forebrain. Neuron 10, 201-212.

Liu, H. K., Belz, T., Bock, D., Takacs, A., Wu, H., Lichter, P., Chai, M., and Schutz, G. (2008). The nuclear receptor tailless is required for neurogenesis in the adult subventricular zone. Genes Dev. 22, 2473-2478.

Liu, X., Bolteus, A. J., Balkin, D. M., Henschel, O., and Bordey, A. (2006). GFAP-expressing cells in the postnatal subventricular zone display a unique glial phenotype intermediate between radial glia and astrocytes. Glia $54,394-410$.

Liu, X., Wang, Q., Haydar, T. F., and Bordey, A. (2005). Nonsynaptic GABA signaling in postnatal subventricular zone controls proliferation of GFAPexpressing progenitors. Nat. Neurosci. 8, 1179-1187.

Lledo, P.M., Alonso, M., and Grubb, M. S. (2006). Adult neurogenesis and functional plasticity in neuronal circuits. Nat. Rev. Neurosci. 7, 179-193.
Lois, C., and Alvarez-Buylla, A. (1994). Long-distance neuronal migration in the adult mammalian brain. Science 264, 1145-1148.

Lois, C., Garcia-Verdugo, J. M., and Alvarez-Buylla, A. (1996). Chain migration of neuronal precursors. Science 271, 978-981.

Luskin, M. B. (1993). Restricted proliferation and migration of postnatally generated neurons derived from the forebrain subventricular zone. Neuron 11, 173-189.

Machold, R., Hayashi, S., Rutlin, M., Muzumdar, M. D., Nery, S., Corbin, J. G., Gritli-Linde, A., Dellovade, T., Porter, J. A., Rubin, L. L., Dudek, H., McMahon, A. P., and Fishell, G. (2003). Sonic hedgehog is required for progenitor cell maintenance in telencephalic stem cell niches. Neuron 39, 937-950.

Mank, M., and Griesbeck, O. (2008). Genetically encoded calcium indicators. Chem. Rev. 108, 1550-1564.

Marshall, C. A., Novitch, B. G., and Goldman, J. E. (2005). Olig2 directs astrocyte and oligodendrocyte formation in postnatal subventricular zone cells. J. Neurosci. 25, 7289-7298.

Marshall, C. A., Suzuki, S. O., and Goldman, J. E. (2003). Gliogenic and neurogenic progenitors of the subventricular zone: who are they, where did they come from, and where are they going? Glia 43, 52-61.

Mercier, F., Kitasako, J. T., and Hatton, G. I. (2002). Anatomy of the brain neurogenic zones revisited: fractones and the fibroblast/macrophage network. J. Comp. Neurol. 451, 170-188.

Merkle, F. T., Mirzadeh, Z., and AlvarezBuylla,A. (2007). Mosaic organization of neural stem cells in the adult brain. Science 317, 381-384.

Merkle, F. T., Tramontin, A. D., GarciaVerdugo, J. M., and Alvarez-Buylla, A. (2004). Radial glia give rise to adult neural stem cells in the subventricular zone. Proc. Natl. Acad. Sci. U.S.A. 101, 17528-17532.

Mignone, J. L., Kukekov, V., Chiang, A. S., Steindler, D., and Enikolopov, G. (2004). Neural stem and progenitor cells in nestin-GFP transgenic mice. J. Comp. Neurol. 469, 311-324.

Mori, T., Tanaka, K., Buffo, A., Wurst, W., Kuhn, R., and Gotz, M. (2006) Inducible gene deletion in astroglia and radial glia - a valuable tool for functional and lineage analysis. Glia 54, 21-34.

Murase, S., and Horwitz, A. F. (2002). Deleted in colorectal carcinoma and differentially expressed integrins mediate the directional migration of neural precursors in the rostral migratory stream. J. Neurosci. 22, 3568-3579. 
Naldini, L. (1998). Lentiviruses as gene transfer agents for delivery to nondividing cells. Curr. Opin. Biotechnol. 9, 457-463.

Nam, S. C., Kim, Y., Dryanovski, D., Walker, A., Goings, G., Woolfrey, K., Kang, S. S., Chu, C., Chenn, A., Erdelyi, F., Szabo, G., Hockberger, P., and Szele, F. G. (2007). Dynamic features of postnatal subventricular zone cell motility: a two-photon time-lapse study. J. Comp. Neurol. 505, 190-208.

Noraberg, J., Jensen, C. V., Bonde, C., Montero, M., Nielsen, J. V., Jensen, N. A., and Zimmer, J. (2007). The developmental expression of fluorescent proteins in organotypic hippocampal slice cultures from transgenic mice and its use in the determination of excitotoxic neurodegeneration. Altern. Lab. Anim. 35, 61-70.

Parras, C. M., Galli, R., Britz, O., Soares, S., Galichet, C., Battiste, J., Johnson, J. E., Nakafuku, M., Vescovi, A., and Guillemot, F. (2004). Mash1 specifies neurons and oligodendrocytes in the postnatal brain. EMBO J. 23, 4495-4505.

Pastrana, E., Cheng, L. C., and Doetsch, F. (2009). Simultaneous prospective purification of adult subventricular zone neural stem cells and their progeny. Proc. Natl. Acad. Sci. U.S.A. 106, 6387-6392.

Paterson, J. A., Privat, A., Ling, E. A., and Leblond, C. P. (1973). Investigation of glial cells in semithin sections. 3 . Transformation of subependymal cells into glial cells, as shown by radioautography after $3 \mathrm{H}$-thymidine injection into the lateral ventricle of the brain of young rats. J. Comp. Neurol. 149, 83-102.

Peretto, P., Giachino, C., Aimar, P., Fasolo, A., and Bonfanti, L. (2005). Chain formation and glial tube assembly in the shift from neonatal to adult subventricular zone of the rodent forebrain. J. Comp. Neurol. 487, 407-427.

Peretto, P., Merighi, A., Fasolo, A., and Bonfanti, L. (1997). Glial tubes in the rostral migratory stream of the adult rat. Brain Res. Bull. 42, 9-21.

Platel, J. C., Dave, K. A., Gordon, V., Lacar, B., Rubio, M. E., and Bordey, A. (2010). NMDA receptors activated by subventricular zone astrocytic glutamate are critical for neuroblast survival prior to entering a synaptic network. Neuron 65, 859-872.

Platel, J. C., Dupuis, A., Boisseau, S., Villaz, M., Albrieux, M., and Brocard, J. (2007a). Synchrony of spontaneous calcium activity in mouse neocortex before synaptogenesis. Eur. J. Neurosci. 25, 920-928.

Platel, J. C., Lacar, B., and Bordey, A. (2007b). GABA and glutamate signaling: homeostatic control of adult forebrain neurogenesis. J. Mol. Histol. 38, 602-610.

Platel, J. C., Gordon, V., Heintz, T., and Bordey, A. (2009). GFAP-GFP neural progenitors are antigenically homogeneous and anchored in their enclosed mosaic niche. Glia 57, 66-78.

Platel, J., Heintz, T., Young, S., Gordon, V., and Bordey, A. (2008). Tonic activation of GLUK5 kainate receptors decreases neuroblast migration in a whole mount preparation of the subventricular zone. J. Physiol. (Lond) 586, 3783-3793.

Polito, A., and Reynolds, R. (2005). NG2expressing cells as oligodendrocyte progenitors in the normal and demyelinated adult central nervous system. J. Anat. 207, 707-716.

Privat, A., and Leblond, C. P. (1972). The subependymal layer and neighboring region in the brain of the young rat. J. Comp. Neurol. 146, 277-302.

Raponi, E., Agenes, F., Delphin, C., Assard, N., Baudier, J., Legraverend, C., and Deloulme, J. C. (2007). S100B expression defines a state in which GFAPexpressing cells lose their neural stem cell potential and acquire a more mature developmental stage. Glia 55, 165-177.

Regan, M. R., Huang, Y. H., Kim, Y. S., Dykes-Hoberg, M. I., Jin, L., Watkins, A. M., Bergles, D. E., and Rothstein, J. D. (2007). Variations in promoter activity reveal a differential expression and physiology of glutamate transporters by glia in the developing and mature CNS. J. Neurosci. 27, 6607-6619.

Roy, N. S., Benraiss, A., Wang, S., Fraser, R. A., Goodman, R., Couldwell, W. T., Nedergaard, M., Kawaguchi, A., Okano, H., and Goldman, S. A. (2000). Promoter-targeted selection and isolation of neural progenitor cells from the adult human ventricular zone. J. Neurosci. Res. 59, 321-331.

Rubinson, D.A., Dillon, C.P., Kwiatkowski, A. V., Sievers, C., Yang, L., Kopinja, J., Rooney, D. L., Zhang, M., Ihrig, M. M., McManus, M. T., Gertler, F. B., Scott, M. L., and Van Parijs, L. (2003). A lentivirus-based system to functionally silence genes in primary mammalian cells, stem cells and transgenic mice by RNA interference. Nat. Genet. 33, 401-406.

Sato, Y., Kasai, T., Nakagawa, S., Tanabe, K., Watanabe, T., Kawakami, K., and Takahashi, Y. (2007). Stable integration and conditional expression of electroporated transgenes in chicken embryos. Dev. Biol. 305, 616-624.

Schmid, R. S., Yokota, Y., and Anton, E. S. (2006). Generation and characterization of brain lipid-binding protein promoter-based transgenic mouse models for the study of radial glia. Glia 53, 345-351.

Smart, I. (1961). The subependymal layer of the mouse brain and its cellular production as shown by radioautography after thymidine-H3 injection. J. Comp. Neurol. 116, 325-349.

Spitzer, N. C. (2006). Electrical activity in early neuronal development. Nature 444, 707-712.

Sucher, N. J., and Deitcher, D. L. (1995). PCR and patch-clamp analysis of single neurons. Neuron 14, 1095-1100.

Sundholm-Peters, N. L., Yang, H. K., Goings, G. E., Walker, A. S., and Szele, F. G. (2004). Radial glia-like cells at the base of the lateral ventricles in adult mice. J. Neurocytol. 33, 153-164.

Tanvig, M., Blaabjerg, M., Andersen, R. K., Villa, A., Rosager, A. M., Poulsen, F. R., Martinez-Serrano, A., Zimmer, J., and Meyer, M. (2009). A brain slice culture model for studies of endogenous and exogenous precursor cell migration in the rostral migratory stream. Brain Res. 1295, 1-12.

Thevenaz, P., Ruttimann, U.E., and Unser, M. (1998).A pyramid approach to subpixel registration based on intensity. IEEE Trans. Image Process. 7, 27-41.

Tian, L., Hires, S. A., Mao, T., Huber, D., Chiappe, M. E., Chalasani, S. H., Petreanu, L., Akerboom, J., McKinney, S. A., Schreiter, E. R., Bargmann, C. I., Jayaraman, V., Svoboda, K., and Looger, L. L. (2009). Imaging neural activity in worms, flies and mice with improved GCaMP calcium indicators. Nat. Methods 6, 875-881.

Tronche, F., Kellendonk, C., Kretz, O., Gass, P., Anlag, K., Orban, P. C., Bock, R., Klein, R., and Schutz, G. (1999). Disruption of the glucocorticoid receptor gene in the nervous system results in reduced anxiety. Nat. Genet. 23, 99-103.

Ventura, R. E., and Goldman, J. E. (2007) Dorsal radial glia generate olfactory bulb interneurons in the postnatal murine brain. J. Neurosci. 27 4297-4302.

Wang, D. D., and Bordey, A. (2008). The astrocyte odyssey. Prog. Neurobiol. 86, 342-367.

Wang, D. D., Krueger, D. D., and Bordey, A. (2003a). Biophysical properties and ionic signature of neuronal progenitors of the postnatal subventricular zone in situ. J. Neurophysiol. 90, 2291-2302.

Wang, D. D., Krueger, D. D., and Bordey,A (2003b). GABA depolarizes neuronal progenitors of the postnatal subventricular zone via GABAA receptor activation. J. Physiol. (Lond) 550, 785-800.

Wang, T. W., Zhang, H., and Parent, J. M. (2005). Retinoic acid regulates postnatal neurogenesis in the murine subven- tricular zone-olfactory bulb pathway. Development 132, 2721-2732.

Wang, X., Qiu, R., Tsark, W., and Lu, Q. (2007). Rapid promoter analysis in developing mouse brain and genetic labeling of young neurons by doublecortin-DsRed-express. J. Neurosci. Res. 85, 3567-3573.

Washbourne, P., and McAllister, A. K. (2002). Techniques for gene transfer into neurons. Curr. Opin. Neurobiol. 12, 566-573.

Yamaguchi, M., Saito, H., Suzuki, M., and Mori, K. (2000). Visualization of neurogenesis in the central nervous system using nestin promoter-GFP transgenic mice. Neuroreport 11, 1991-1996.

Young, S. Z., Platel, J. C., Nielsen, J. V., Jensen, N. A., Bordey, A. (2010). GABAA increases calcium in subventricular zone astrocyte-like cells through L- and T-type voltage-gated calcium channels. Front. Cell. Neurosci. 4:8. doi: 10.3389/fncel.2010.00008.

Yu, T. S., Dandekar, M., Monteggia, L. M., Parada, L. F., and Kernie, S. G. (2005). Temporally regulated expression of Cre recombinase in neural stem cells. Genesis 41, 147-153.

Zhao, C., Deng, W., and Gage, F.H. (2008). Mechanisms and functional implications of adult neurogenesis. Cell 132, 645-660.

Zhu, X., Bergles, D. E., and Nishiyama, A. (2008). NG2 cells generate both oligodendrocytes and gray matter astrocytes. Development 135, 145-157.

Zhuo, L., Sun, B., Zhang, C. L., Fine, A., Chiu, S. Y., and Messing, A. (1997). Live astrocytes visualized by green fluorescent protein in transgenic mice. Dev. Biol. 187, 36-42.

Conflict of Interest Statement: The authors declare that the research was conducted in the absence of any commercial or financial relationships that could be construed as a potential conflict of interest.

Received: 17 April 2010; paper pending published: 11 May 2010; accepted: 08 June 2010; published online: 19 July 2010. Citation: Lacar B, Young SZ, Platel J-C and Bordey A (2010) Imaging and recording subventricular zone progenitor cells in live tissue of postnatal mice. Front. Neurosci. 4:43. doi: 10.3389/fnins.2010.00043

This article was submitted to Frontiers in Neurogenesis, a specialty of Frontiers in Neuroscience.

Copyright $@ 2010$ Lacar, Young, Platel and Bordey. This is an open-access article subject to an exclusive license agreement between the authors and the Frontiers Research Foundation, which permits unrestricted use, distribution, and reproduction in any medium, provided the original authors and source are credited. 